\title{
Allergic aspergillosis of the respiratory tract
}

\author{
Ashok Shah ${ }^{1}$ and Chandramani Panjabi²
}

Affiliations: 'Dept of Respiratory Medicine, Vallabhbhai Patel Chest Institute, University of Delhi, New Delhi, and ${ }^{2}$ Dept of Respiratory Medicine, Mata Chanan Devi Hospital, New Delhi, India.

Correspondence: A. Shah, Dept of Respiratory Medicine, Vallabhbhai Patel Chest Institute, University of Delhi, Delhi 110 007, P.O. Box 2101, India. E-mail: ashokshah99dyahoo.com

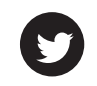

@ERSpublications

Aspergillus sensitive asthmatics must be investigated for ABPA and allergic Aspergillus sinusitis http://ow.ly/rCC2e

Aspergillus, a genus of spore forming fungi found worldwide, affects the respiratory tract in many ways $[1,2]$. The spores of this ubiquitous mould are dispersed by wind in the atmosphere and inhalation is the primary route of access in almost all forms of aspergillosis. The spectrum of Aspergillus-associated respiratory disorders comprises three well defined clinical categories (table 1): allergic manifestations, saprophytic colonisation of the respiratory tract and invasive disseminated disease [1]. Amongst the allergic aspergillosis disorders, allergic bronchopulmonary aspergillosis (ABPA) is the most recognised form. Since it was first described in England, UK, in 1952 [3], it has been documented around the world [4]. Although ABPA and allergic Aspergillus sinusitis (AAS) are mostly encountered in atopic individuals, hypersensitivity pneumonitis can occur in the nonatopic population.

\section{Aspergillus-induced asthma}

Aspergillus-induced asthma (AIA) is a classical immediate (type I) IgE-mediated hypersensitivity reaction to Aspergillus antigens that presents clinically as asthma. The frequency of Aspergillus sensitisation in asthmatic subjects varies from $16 \%$ to $38 \%$ in different geographical regions [5-8]. In a trans-Atlantic comparison study, type I skin reactivity to Aspergillus antigens was elicited in $28 \%$ of asthmatic patients from Cleveland (OH, USA) and 23\% from London, UK [7]. The authors were surprised at finding a direct correlation between Aspergillus skin-test positivity and severity of airflow obstruction. In a series of 105 patients with bronchial asthma, 30 (28.5\%) were sensitised to Aspergillus antigens [8]. This group of 30 patients with AIA had a more severe form of asthma when compared to those with skin test positivity to antigens other than Aspergillus. This was evidenced by a statistically significant higher mean duration of illness $(\mathrm{p}<0.001)$, mean eosinophil count $(\mathrm{p}<0.0001)$, mean total $\operatorname{IgE}(\mathrm{p}<0.05)$ and more usage of oral corticosteroids per year $(\mathrm{p}<0.004)$. Thus, it is imperative to assess for Aspergillus sensitisation in patients with asthma. Recently, various studies have found increasing severity of airways obstruction, as well as an increased incidence of bronchiectasis in patients with AIA [9-12].

Severe asthma with fungal sensitisation

It is now well established that sensitisation to various fungi predisposes to an increased severity of bronchial asthma [13, 14]. In a multicentre European Community Respiratory Health Survey trial [13] amongst 1132 adults with asthma, the risk for developing severe asthma was higher in those sensitised to Alternaria alternata and/or Cladosporium herbarum. In the subset of the population with severe asthma, the prevalence

Received: Sept 242013 | Accepted after revision: Dec 042013

Conflict of interest: None declared.

Provenance: Submitted article, peer reviewed.

Copyright OERS 2014. ERR articles are open access and distributed under the terms of the Creative Commons Attribution Non-Commercial Licence 3.0. 
TABLE 1 Aspergillus-associated respiratory disorders

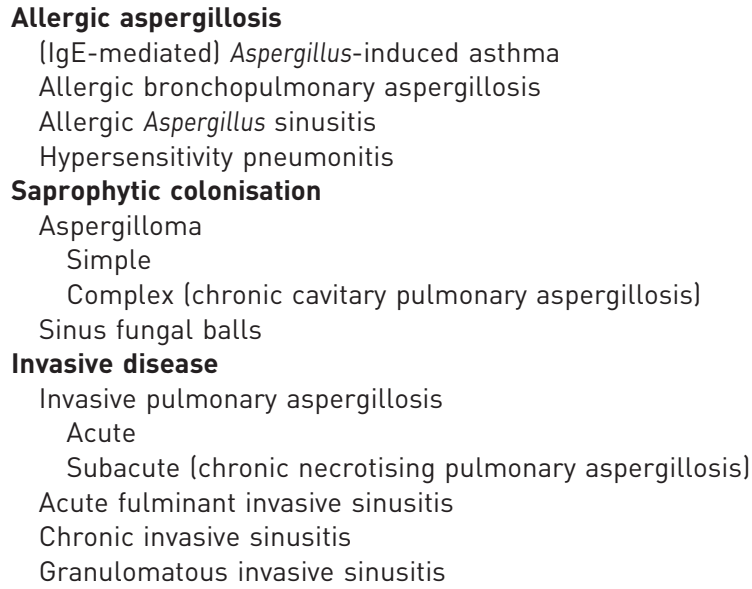

Information from [1, 2].

of fungal sensitisation was much higher and ranged up to $75 \%$ in those requiring multiple hospitalisations. Since this could have clinico-therapeutic implications, a separate entity called severe asthma with fungal sensitisation (SAFS) was described [15].

The diagnostic criteria for SAFS include: 1) severe (poorly controlled) asthma; 2) a positive skin-prick test result for fungi (but not necessarily to Aspergillus species) or in vitro demonstration of antifungal $\operatorname{IgE}$ of at least $0.4 \mathrm{kU} \cdot \mathrm{L}^{-1}$; and 3) a total serum IgE concentration $<1000 \mathrm{kU} \cdot \mathrm{L}^{-1}$ [15]. Although cutaneous positivity to one or more fungi is elicited in patients with SAFS, bronchiectasis and mucoid impaction are generally absent and serum precipitins to Aspergillus are negative. There appears to be a promising role for antifungal agents in these patients $[16,17]$. Statistically significant better asthma quality of life scores were noted in a randomised controlled trial when itraconazole $200 \mathrm{mg}$ twice daily was prescribed for 32 weeks in patients with SAFS [16].

It is also important to distinguish between SAFS and ABPA [15]. It appears that SAFS may be a completely different entity as ABPA can also occur in mild or moderate asthmatics. In a recent perspective, GREENBERGER [18] dwelled on the distinction between SAFS and ABPA. It is still not known how many patients with SAFS will eventually progress to ABPA/allergic bronchopulmonary mycoses (ABPM).

\section{Allergic bronchopulmonary aspergillosis}

An immunologically mediated lung disease, ABPA predominantly affects patients with asthma and cystic fibrosis (CF) [19]. Repeated inhalation of Aspergillus spores, principally Aspergillus fumigatus, leads to airway colonisation in susceptible hosts that elicits an allergic response. Although type I (IgE-mediated) hypersensitivity is common, type III (IgG-mediated immune complex) and type IV (cell-mediated) reactions have also been observed; however, tissue invasion does not occur [20]. The different Aspergillus species, which belong to a genus of ubiquitous spore forming fungi, are present in both the indoor and outdoor environment. Exposure to aspergilli from municipal leaf compost heaps [21] and garbage collection sites [22] has led to the development of ABPA. Other areas with high Aspergillus load include damp basements, barns and sewage treatment facilities.

Despite ABPA being recognised as a disease that predominantly affects asthmatics more than six decades ago, we have been unable to answer the question of why only a few asthmatics actually suffer from this potentially destructive lung disease. Furthermore, asthma is well known to run in families but familial occurrence of ABPA remains a rarity [23, 24]. Evaluation of 164 patients diagnosed over a period of 22 years at a tertiary referral centre detected familial occurrence in four (4.9\%) pairs of first degree relatives. Concomitant AAS was present in one patient each in three out of the four pairs [25]. Even today, ABPA remains a challenge to the pulmonologist as consensus on appropriate standardised diagnostic criteria and management protocols are still emerging.

\section{Immunopathogenesis}

As mentioned previously, it remains a mystery as to why only a few patients with asthma develop ABPA. Genetic predisposition may possibly be involved as is suggested by the familial occurrence. Spores of 
Aspergillus get trapped in the viscid sputum and colonise the airways of susceptible patients with asthma. After colonisation, the conidia of this thermotolerant species germinate within the airways and form hyphae. This results in secretion of proteolytic enzymes that mediate the release of proinflammatory cytokines [26]. A polyclonal antibody response is evoked, leading to elevated total $\operatorname{IgE}$ and Aspergillus-specific IgE, IgG and IgA antibodies [27]. Increased in vitro synthesis of $\operatorname{IgE}$ by B-lymphocytes was found in patients with ABPA when compared to patients with AIA [28]. The immunological response is primarily of the cellular T-helper cell (Th)-2 type, as evident by increased interleukin (IL)-4, IL-5, IL-10 and IL-13 production. Thus, the strong humoral and cellular response that is elicited indicates that the patient is immunocompetent and possesses an activated defence system against the offending fungi $[29,30]$.

Various genetic and host susceptibility factors play a role in determining which Aspergillus sensitised patients go on to develop ABPA. Specific antibodies to a cytotoxic ribonuclease antigen (18 kD) and an elastinolytic protease antigen $(45 \mathrm{kD})$ were observed in Indian patients with ABPA [31,32]. Earlier studies found a strong association between human leukocyte antigen (HLA)-DR2/DR5 genotypes and ABPA when compared to patients with asthma but without ABPA [33-35]. A specific HLA-DR2 (DRB1^1503) allele was almost exclusively identified in ABPA while HLA-DQ2 had a protective role [35]. Mutations in the cystic fibrosis transmembrane conductance regulator (CFTR) gene were found in patients with ABPA and CF [36-39]. The CFTR mutations resulted in abnormal mucus properties when the bronchi of such patients were subjected to a heavy load of Aspergillus spores and hyphae [40].

Subsequent studies have linked genetic polymorphisms to the heightened Th2 cellular response in ABPA. The role of lung surfactant proteins (SP) A and D in inhibiting the ability of allergic-specific IgE from patients with ABPA was demonstrated [41, 42]. An association between SP-A2 polymorphisms and increased levels of IgE and eosinophils was also found [43, 44]. Two exonic polymorphisms SP-A2 A1660G and SP-A2 G1649C were associated with an increased severity of clinical markers [43]. Single nucleotide polymorphisms of IL-4 receptor- $\alpha(\mathrm{IL}-4 \mathrm{R} \alpha)[45]$ and IL-10 [46, 47] strongly correlated with ABPA. The IL-10 1082GG genotype was significantly higher in subjects with A. fumigatus colonisation [46]. Elevated levels of mannan-binding lectin, especially the 1011A allele, are also found in ABPA [48, 49]. Toll-like receptor polymorphisms were also demonstrated in patients with ABPA [50].

A synthetic peptide epitope of Asp f 1, a major antigen of A. fumigatus, has been identified for its potential use in skin testing and development of a standardised immunodiagnostic test for aspergillosis [51]. Using the immunoproteomics approach [52], several novel allergens of A. fumigatus were identified that would facilitate serodiagnosis and could potentially help in the development of immunotherapy for ABPA.

\section{Epidemiology of ABPA}

Although ABPA is a well-established entity, its exact prevalence among asthmatics is yet to be estimated. The lack of a uniform diagnostic criterion and standardised tests has hampered efforts on this score [53]. This is highlighted by the fact that ABPA is still to receive recognition in the international classification of diseases, the ninth revision of which, in 1996, did not include ABPA [54]. In the initial years between 1959 and 1968, when awareness regarding ABPA outside Europe was low, the prevalence of definite ABPA among patients with asthma in England was estimated to be $\sim 8-11 \%$ while that of probable ABPA was $\sim 22 \%$ [55]. In 1971, researchers from Australia highlighted the difficulty in determining the prevalence of ABPA [56], which was seen in nearly $10 \%$ of their 250 asthmatic subjects. After recognition of this entity from the USA in 1968 [57], several studies determined sensitisation to Aspergillus antigens in patients with asthma. Between 1983 and 1986, Greenberger and Patterson [58] evaluated 531 patients with asthma and immediate cutaneous reactivity to Aspergillus antigens. A diagnosis of ABPA was made in 32 (6\%) patients, 19 (3.6\%) with central bronchiectasis and $13(2.4 \%)$ with positive serology only. In subsequent studies [8, 59, 60], ABPA was detected in $25-37 \%$ of asthmatics with a positive skin-prick test to A. fumigatus. In 105 patients with bronchial asthma [8], a significantly longer duration of illness and earlier age of onset of asthma, as well as rhinitis, higher mean total leukocyte counts, absolute eosinophil counts and total serum IgE values were found in eight patients diagnosed with ABPA. In addition, this group had significantly more patients with severe obstructive airways disease and had significantly more prescriptions for oral corticosteroids.

According to internationally available data, ABPA may be found in up to $6 \%$ of all asthmatic patients [61]. In $\mathrm{CF}$, the prevalence of ABPA ranges from $2 \%$ to $15 \%$ [62]. In an attempt to ascertain the global burden of ABPA, DENNING et al. [63] conducted a scoping review by utilising published clinical and population-based studies on asthma and ABPA. Data analyses from five referral cohorts [60, 64-67], which were prospective studies on estimating the frequency of ABPA in at least 50 patients with asthma, revealed that the prevalence of ABPA in adult asthmatics is $2.5 \%$ (range $0.72-3.5 \%$ ). Based on this model, the authors opined that the number of adult patients with ABPA throughout the world could "potentially exceed 4.8 million" [63]. 
In order to formulate consensus-based guidelines for the diagnosis and treatment of ABPA, in September 2011, the International Society for Human and Animal Mycology (ISHAM) established a working group on ABPA complicating asthma. Compiling published data on Aspergillus sensitisation and ABPA since 2000, the ISHAM working group [68] found that the prevalence of Aspergillus sensitisation among asthmatics varied between $5.5 \%$ and $38.5 \%$ [8,60,66, 67, 69-72]. During the same period, the prevalence of ABPA in patients with asthma ranged from $2.5 \%$ to $22.3 \%$ with a pooled prevalence of $8.4 \%$ [68]. The working group went on to propose a revised set of diagnostic criteria, which is discussed below [68].

\section{Diagnostic criteria}

The major and minor diagnostic criteria for ABPA have evolved over time (table 2) [73, 74]. A set of criteria is required as, apart from demonstration of central bronchiectasis with normal tapering bronchi, there is no single test that establishes the diagnosis or is not affected by therapy with oral prednisolone [75]. The occurrence of central bronchiectasis with normal tapering bronchi in ABPA was first described by SCADDING [76], and is considered to be pathognomonic of the disease. A set of minimal essential criteria has also been advocated by GREENBERGER [19], which includes: 1) asthma, 2) immediate cutaneous reactivity to A. fumigatus, 3) total serum IgE $\left.>1000 \mathrm{ng} \cdot \mathrm{mL}^{-1}\left(417 \mathrm{kU} \cdot \mathrm{L}^{-1}\right), 4\right)$ elevated specific IgE-/IgG-A. fumigatus, and 5) central bronchiectasis in the absence of distal bronchiectasis. When central bronchiectasis is not present, the disease entity is termed serological ABPA, which could possibly be an earlier or a milder form of presentation [77]. GREENBERGER [18] has further suggested that minimal essential criteria 1-3 and 5 could possibly be considered as "truly minimal" diagnostic criteria.

Even though the initial criteria were formed three decades ago, the best cut-off values of total $\operatorname{IgE}$ and eosinophil count, as well as the specificity of IgG-A. fumigatus, for ABPA are not truly known. Moreover, a lack of any consensus on the minimum number of criteria, either major or minor, required to confirm the presence of ABPA still exists. In order to overcome these gaps, the ISHAM working group [68] has proposed revised criteria for the diagnosis of ABPA wherein the items are broadly divided into "obligatory" and "other" criteria (table 2). This newly proposed set of criteria recognises bronchial asthma and CF as predisposing conditions for ABPA. The two features of the obligatory criteria are: 1) positive immediate (type I) cutaneous hypersensitivity to Aspergillus antigen or elevated IgE levels against A. fumigatus, and 2) elevated total $\mathrm{IgE}$ levels $>1000 \mathrm{IU} \cdot \mathrm{mL}^{-1}$. It is essential that both these findings should be present to achieve a diagnosis of ABPA. At least two out of three other criteria should be fulfilled: 1) the presence of precipitating or IgG antibodies against A. fumigatus in serum, 2) radiographic pulmonary opacities consistent with $\mathrm{ABPA}$, and 3 ) a total eosinophil count $>500$ cells $\cdot \mu \mathrm{L}^{-1}$ in steroid naive patients. This set of criteria is aimed to help clinicians establish an early diagnosis. However, the working group has suggested that this newly proposed criteria needs "validation and further refinement" [68].

\section{ABPA without asthma}

Although asthma is generally the first criterion for diagnosis; on rare occasions, ABPA may occur in subjects without clinical asthma. In 1981, GLANCY et al. [78] described the first such patient. Since then approximately a score of patients with ABPA without asthma have been reported [79-83]. On the basis of their clinical and radiological findings, more than half of these patients were initially investigated for bronchogenic carcinoma while one patient was referred for evaluation of multidrug-resistant tuberculosis [82]. This could be attributed to the absence of clinical asthma and the remarkable radiological similarities to pulmonary tuberculosis. A patient with ABPA without asthma but with bronchlithiasis was also described from Korea [83].

\section{Clinical features}

An indolent disease with a protracted course, ABPA can range from mild symptoms of airways obstruction to fatal destructive lung disease. Apart from asthma, ABPA may also be associated with other clinical atopic conditions [84]. Usually seen in the 20-40-year age group, ABPA has also been reported in children [85, 86] and even in infants [87]. Repeated episodes of asthmatic exacerbations interspersed with periods of remissions are observed which, if untreated, eventually culminate in a fibrotic lung disease resembling the chronic fibrocavitary disease of pulmonary tuberculosis [88].

Expectoration of golden-brown plugs in the sputum, especially in poorly controlled asthmatics with peripheral eosinophilia, strongly suggests the possibility of ABPA [89]. The symptomatic presentation however, appears to bear little or no relationship to the severity or chronicity of the disease, as a third of the patients may be relatively asymptomatic despite extensive radiological lesions [90]. In an analysis of 113 patients with ABPA [91], 70 of whom were males, the mean age of the patients was 32 years while the mean age of asthma onset was 21 years. Cough (99\%) and breathlessness (99\%) were the commonest symptoms, followed by expectoration (98\%), wheezing (97\%) and haemoptysis (41\%). Fever was seen in $80 \%$ and nasal 


\section{TABLE 2 Evolving diagnostic criteria for allergic bronchopulmonary asperillosis (ABPA)}

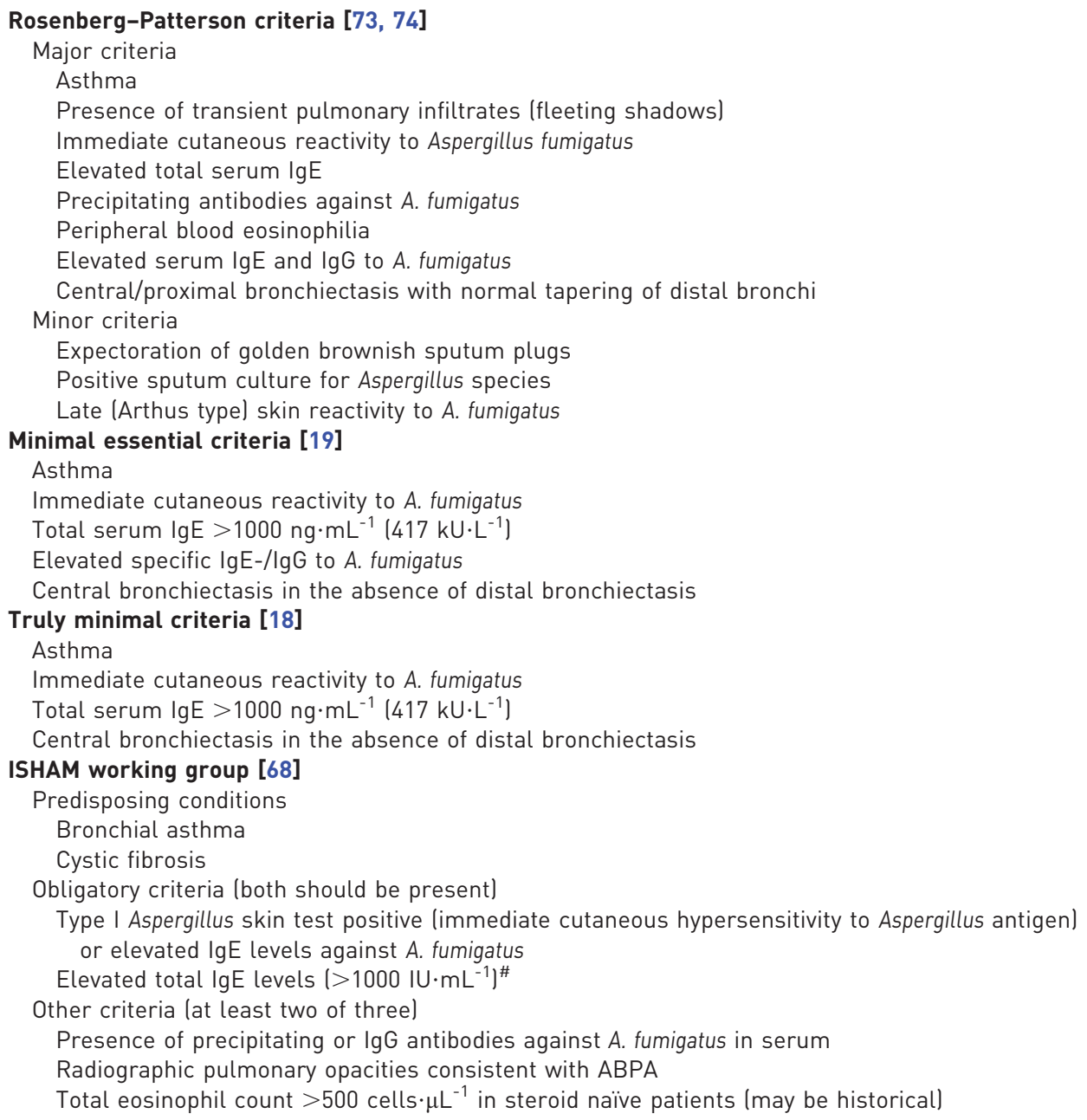

ISHAM: International Society for Human and Animal Mycology. ${ }^{\#}$ : if the patient meets all other criteria an $\operatorname{lgE}$ value $<1000 \mathrm{IU} \cdot \mathrm{mL}^{-1}$ may be acceptable.

symptoms in $45 \%$. Sputum plugs were expectorated by $37 \%$ and nasal plugs by $6 \%$. A personal/family history of atopic diseases was present in approximately half of the patients.

\section{Radiological manifestations}

Although ABPA is now a well-recognised pulmonary disease, it is not yet diagnosed as frequently and as early as it should be; thereby causing preventable chronic lung damage [92]. Ever since its first description, imaging techniques have played a pivotal role for the diagnosis and monitoring of ABPA [93, 94].

\section{Plain chest radiography}

ABPA can be regarded as a "picturesque" disease because of the wide spectrum of appearances seen on chest radiography [94-97]. These images can be either transient or permanent (table 3). In their seminal description of ABPA in 1952, HinsON et al. [3] recognised fleeting shadows as a characteristic feature of this disease. These opacities usually appear and disappear in different areas of the lung over a period of time and are also known as transient pulmonary infiltrates (figs 1 and 2). In a review of 1340 chest radiographs from 113 patients with ABPA, fleeting shadows were observed in 89\% [91]. These changes, usually seen in either the acute or exacerbation stage of the disease, indicate the presence of an active disease process. Mucoid impaction causes this phenomenon, which is due to secretions in the damaged bronchi. These infiltrates may clear with or without therapy. Although these radiological appearances can closely resemble those seen in tuberculosis, serial radiographs in ABPA may reveal the transient nature of these migratory infiltrates [94]. When these opacities keep recurring at the same sites they are described as recurrent fixed shadows [98]. 
TABLE 3 Radiological changes in allergic bronchopulmonary asperillosis

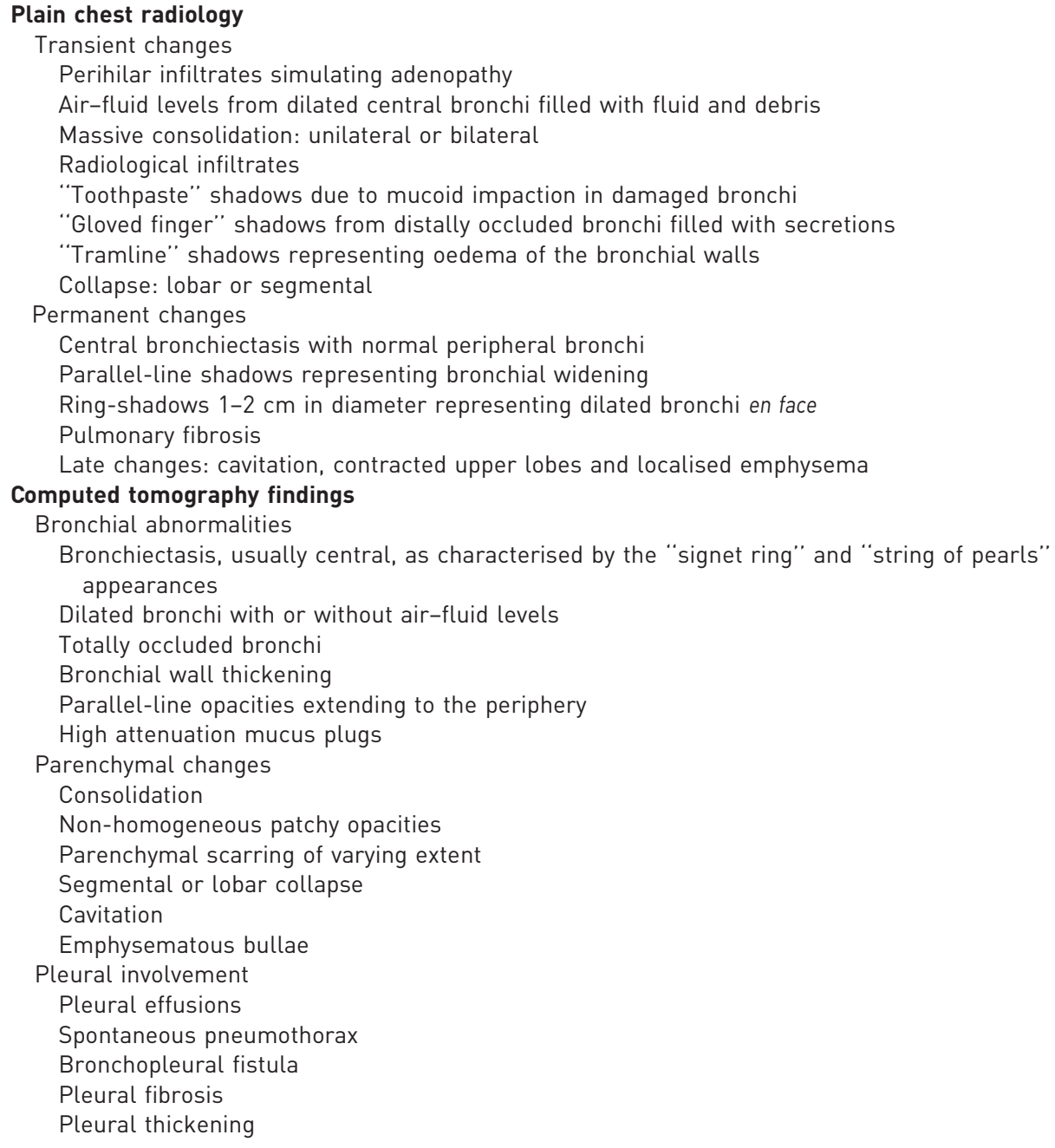

Information from [1, 93].

Consolidation or non-homogeneous infiltrations are the most commonly observed patterns, described in up to $91 \%$ of patients with ABPA [91, 95-97]. Perihilar or pseudohilar infiltrates may simulate hilar adenopathy in ABPA. These infiltrates are found in $40-77 \%$ of patients [91, 96], and are seen surrounding the secretion-filled dilated central bronchi. True hilar adenopathy, which resolved on therapy, was also documented in ABPA in adults $[99,100]$, as well as a single report in a 3.5-year-old child [86]. The presence of other features including tramline sign, V-Y shaped or wine glass shadows (fig. 3), toothpaste shadows and gloved finger shadows should raise the possibility of ABPA. Wine glass shadows were observed in $27 \%$ of 113 patients from India [91]. Lobar or segmental collapse is not uncommon. A patient with concomitant ABPA and AAS presenting as a middle lobe syndrome has been described previously [101]. The permanent opacities reflect the irreversible fibrotic changes and tend to persist throughout life. The most pathognomonic of these is the occurrence of central bronchiectasis with normal peripheral bronchi, and is considered as the sine qua non for the diagnosis of ABPA in patients without CF [102].

\section{Demonstration of central bronchiectasis}

When ABPA is suspected, the pulmonologist almost always immediately searches for the presence of central bronchiectasis, as this feature, when present, is considered to be diagnostic of the disease. On plain chest radiographs, central bronchiectasis is seen either as parallel line opacities, representing widening of the bronchi, or as ring opacities $1-2 \mathrm{~cm}$ in diameter, representing dilated bronchi en face. Parallel line shadows were observed in 65-70\% of patients with ABPA [91, 95, 96] and ring shadows in 45-68\% 


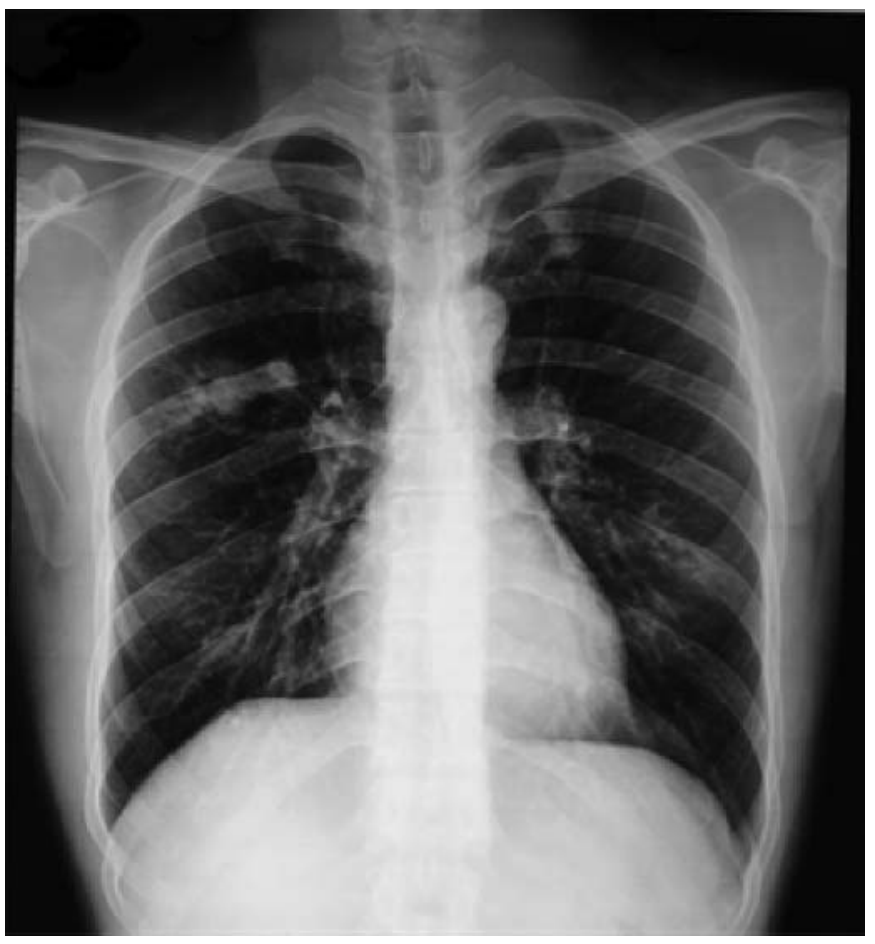

FIGURE 1 Chest radiograph showing a non-homogeneous opacity in the right mid zone with perihilar patchy infiltrates in the left mid and lower zones. Transient pulmonary infiltrates or fleeting shadows that are characteristic of allergic bronchopulmonary asperillosis are visible.

[91, 95-97]. Bronchography, once regarded as the reference standard for the demonstration of central bronchiectasis, gave a one-time complete picture of the entire tracheobronchial tree [103]. Earlier, linear tomography was also used to document central bronchiectasis [104]. Both these methods have now been replaced by computed tomography (CT). High-resolution CT, in particular, has emerged as the investigation of choice for the demonstration of bronchiectasis $[93,103]$. It has already been shown that $\mathrm{CT}$, in comparison to bronchography, a procedure thought to be unsafe in asthma, has a sensitivity of $83 \%$ and a specificity of $92 \%$ in detecting central bronchiectasis in patients with ABPA [103]. CT scans also enabled rapid and safe establishment of diagnosis in children with ABPA who presented with acute severe asthma [105].

On CT, bronchiectasis is characterised by the signet ring (fig. 4a) and string of pearls (fig. 4b) appearances [106]. In ABPA, bronchiectasis tends to be more common in the upper lobes [93, 107] in contrast to the "usual" bronchiectasis that predominantly affects the lower lobes. In an arbitrary classification, bronchiectasis was considered to be central when limited to only the medial two-thirds or medial half of the lung [108]. Extension of central bronchiectasis to the periphery was observed in $30 \%$ of the lobes and $21 \%$ of the segments [91]. However, demonstration of central bronchiectasis with normal peripheral bronchi, which occurred in the majority of segments, should continue, in our opinion, to be regarded as a sine qua non for ABPA [102].

\section{Other CT findings}

Apart from bronchiectasis, other bronchial findings include dilated bronchi with or without air-fluid levels, totally occluded bronchi, bronchial wall thickening and parallel line opacities extending to the periphery. The parenchymal abnormalities mainly include consolidation, non-homogeneous patchy opacities and parenchymal scarring of varying extent. Segmental or lobar collapse, cavitation, fibrosis, contracted upper lobes and localised emphysema are not uncommon [94]. The fibrotic stage of ABPA may be difficult to distinguish from fibrocavitary pulmonary tuberculosis $[85,109,110]$.

\section{High-attenuation mucus plugging}

With the advent of high-resolution CT, high-attenuation mucus (HAM) plugging (fig. 5) was also noted in up to $28 \%$ of patients with ABPA [111]. The mucus plug is said to be hyperattenuating if it is visibly denser than the paraspinal skeletal muscle. This characteristic CT finding has now been highlighted by the ISHAM working group as a pathognomonic feature of ABPA [68]. An analysis of 155 patients with ABPA revealed that patients with HAM had significantly higher levels of eosinophils, total IgE and IgE-A. fumigatus at the time of diagnosis [69]. 
FIGURE 2 Chest radiograph of the same patient as in figure 1 taken 18 months later showing a large consolidation in the right upper and mid zones with partial resolution of the left-sided perihilar infiltrate. In addition, blunting of the right costophrenic angle suggestive of pleural effusion can be seen. Transient pulmonary infiltrates or fleeting shadows that are characteristic of allergic bronchopulmonary asperillosis are visible.

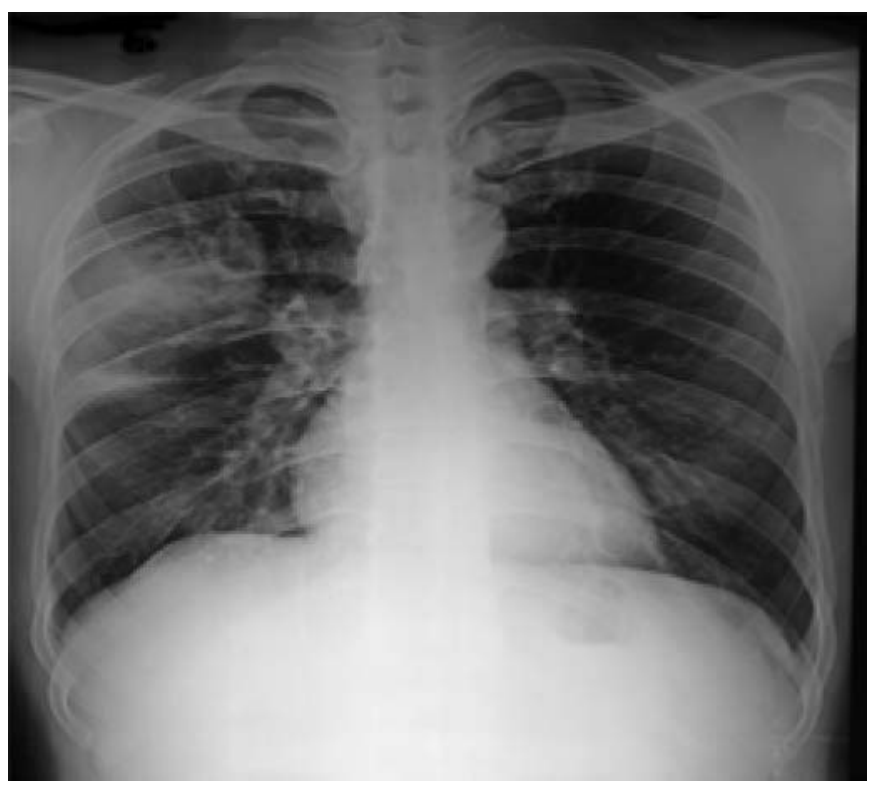

\section{Pleural involvement}

Pleural effusions were first highlighted in two patients with ABPA in 1981 [112]. Ipsilateral pleural effusion, most likely due to the mechanical effect of lung collapse, in a patient with ABPA, AAS and an operated aspergilloma has also been described previously [113]. Therapy with steroids led to resolution of the effusion followed by re-expansion of the affected lobe. Bilateral asymmetrical pleural effusion was also reported in a young adult male [114]. The authors postulated that the fluid collection resulted "from an inflammatory pleural reaction adjacent to inflamed lung tissue" Other pleural findings in ABPA include spontaneous pneumothorax [115], bronchopleural fistula [116] and pleural fibrosis [93, 117]. Pleural based lesions were seen on CT in $43 \%$ of patients [93]. Another study found pleural thickening in $82 \%$ of subjects with ABPA [118]. Although pleural involvement does not appear to have much clinical significance, this aspect of ABPA is yet to be highlighted.

\section{Laboratory findings}

In addition to radiology, other investigations utilised for the diagnosis and monitoring of ABPA include skin testing with Aspergillus antigens, peripheral eosinophil count, serum total IgE, A. fumigatus-specific IgE and IgG, and precipitating antibodies against A. fumigatus. Sputum examination often provides an important clue in patients with asthma and CF.

FIGURE 3 Chest radiograph showing characteristic wine glass opacity in the left upper zone. A non-homogeneous consolidation is also seen on the right side.

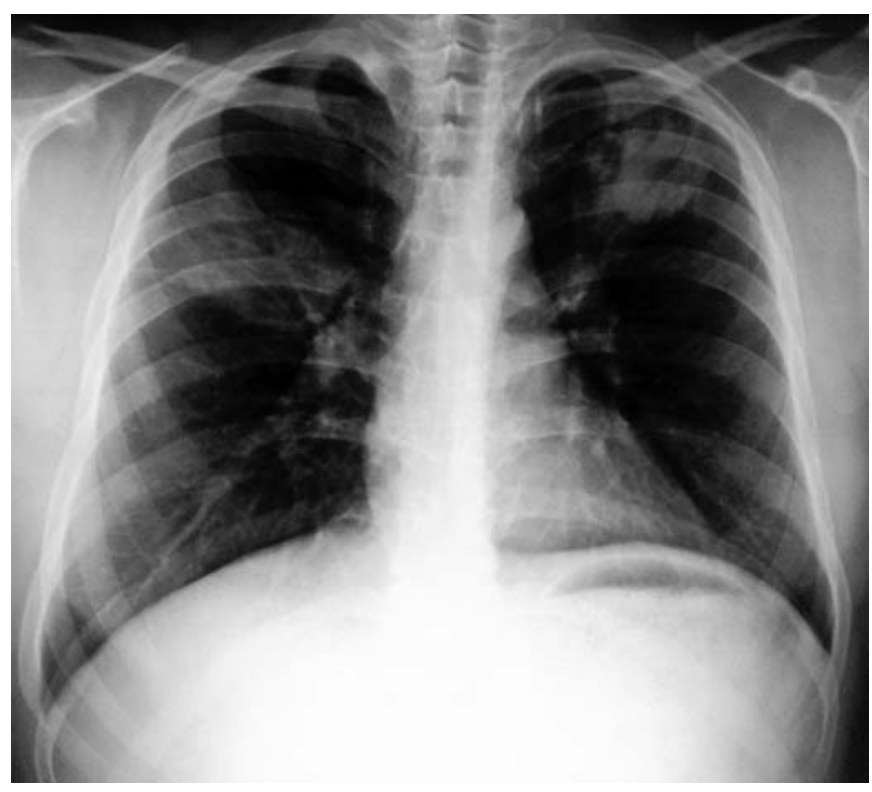



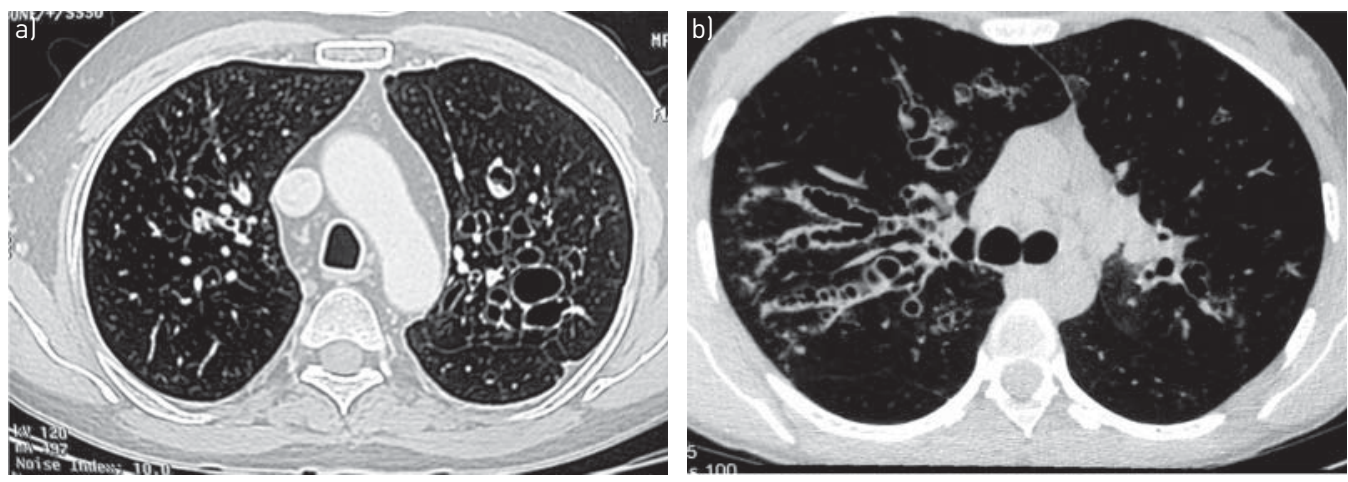

FIGURE 4 a) Computed tomography of the thorax showing signet ring appearances, indicative of central bronchiectasis. Mucoid impaction and dilated bronchi are also visible. b) Computed tomography of the thorax showing string of pearls appearances bilaterally, indicative of central bronchiectasis.

\section{Skin testing}

Hinson et al. [3] stated that cutaneous hypersensitivity reactions with fungal extracts were "inconstant and unreliable" in all three of their patients. Since ABPA is basically an allergic response to Aspergillus antigens, skin sensitivity to Aspergillus was subsequently demonstrated in almost all patients with ABPA described to date. Although more than 150 species of Aspergillus exist, the main incriminating species are A. fumigatus followed by A. flavus, A. niger, A. terreus, and A. nidulans. Either the skin-prick test or the intradermal method can be employed for Aspergillus skin testing. There exists a marked variation in the Aspergillus antigen extract used for skin testing. This depends on the technique, potency and the geographical region [119]. These factors, along with the type of test performed, expertise in interpretation of readings and patients' age variations, are reflected in the accuracy of the results [120]. Although intradermal tests are more sensitive than the skin-prick tests, higher false positive results are noted. Currently, the skin-prick test is the favoured technique, serving as a simple screening tool for ABPA. If the skin-prick test is negative, then intradermal testing may be conducted to exclude Aspergillus sensitisation.

Both type I (immediate) and type III (delayed) responses can be observed in ABPA. In the first ever large series of 111 patients with ABPA published in 1971 [89], type I skin-prick sensitivity with A. fumingatus antigens was seen in all cases and with A. terreus in $92(83 \%)$ cases. The type III reaction to A. fumigatus was positive in $16 \%$ of the patients. Intradermal testing with $A$. fumigatus extract, performed in 80 patients, also elicited immediate (type I) reactions in $100 \%$ and delayed (type III) hypersensitivity in $97 \%$. Although the type III reaction was completely suppressed after therapy with corticosteroids, there was no effect on the type I response even after intensive treatment. Since skin-prick testing is a highly sensitive test for ABPA, a negative result in asthmatic subjects would essentially rule out the possibility of AIA or ABPA. Thus, Aspergillus skin testing would be very helpful in clinical decision making when patients with asthma are screened for ABPA [18]. However, negative skin sensitivity to Aspergillus antigens would not rule out ABPM.

Currently, recombinant A. fumigatus allergens have been cloned, purified and standardised for testing. Although they have similar functional characteristics to the commercially available fungal extracts, these recombinant allergens help in differentiating ABPA from Aspergillus sensitisation in patients with asthma
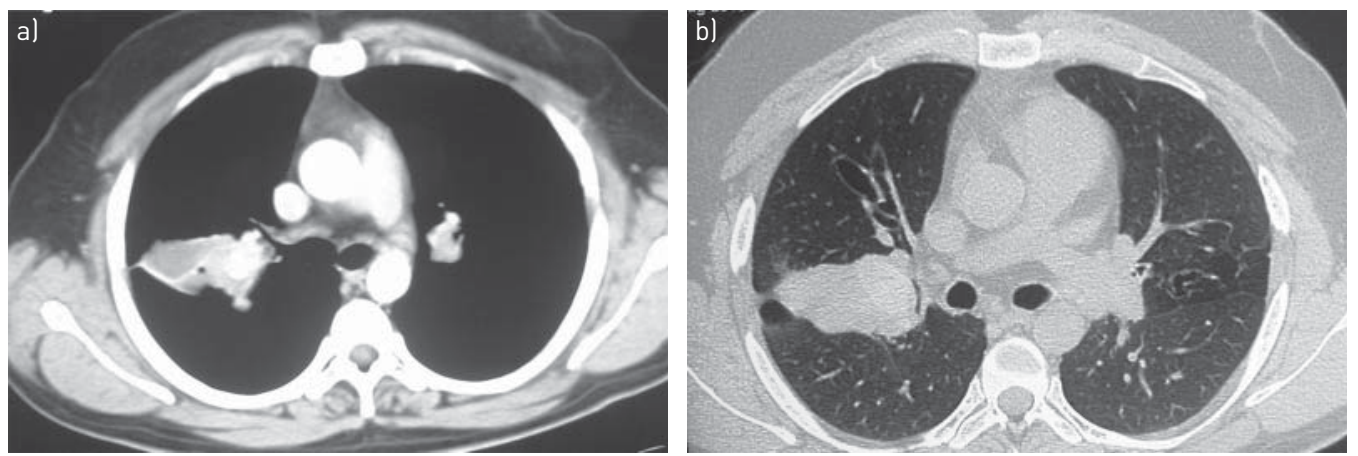

FIGURE 5 High-resolution computed tomography of the thorax a) mediastinal window and b) corresponding section on the lung window showing high attenuation mucus impaction. 
and CF. This differentiation is important as type I sensitivity can be demonstrated in up to $\sim 40 \%$ of all asthmatics [68] and in up to 56\% of patients with CF [121]. Amongst all the A. fumigatus sensitised patients with $\mathrm{CF}$, three out of six patients with associated ABPA were negative on skin-prick testing with recombinant $A$. fumigatus allergen I/a (rAsp f I/a) [122]. In another study in 50 patients with CF (12 with ABPA, 17 with Aspergillus sensitisation without ABPA, and 21 not sensitised to A. fumigatus), skin reactivity to 1:100 or higher dilutions of the cloned rAsp $\mathrm{f} 4$ and rAsp $\mathrm{f} 6$ was not observed in any of the 38 patients without ABPA [123]. These two recombinant allergens were found to be reliable markers for ABPA in CF.

\section{Eosinophil count}

Peripheral blood eosinophilia $\left(>1000\right.$ cells $\left.\cdot \mu \mathrm{L}^{-1}\right)$, one of the major diagnostic criteria, is often the initial diagnostic indicator in a patient with asthma and fleeting pulmonary infiltrates. However, high eosinophil counts may be observed in numerous other diseases while normal levels may be found in patients who are already receiving oral corticosteroids. Given the poor specificity of this test, The ISHAM working group [68] has relegated eosinophilia to "other" criteria. During exacerbations, when oral corticosteroids have not been initiated, most patients have an absolute eosinophil count ranging between 1000 and $3000 \mathrm{cells} \cdot \mathrm{mm}^{-3}$, which may return to near normal with oral corticosteroids.

\section{Total serum IgE}

Elevated total serum IgE is a part of the minimal essential criteria [19], as well one of the truly minimal criteria [18], for diagnosis. Any patient with active disease is unlikely to have a normal IgE level. Although more than four decades have elapsed since its recognition as one of the major criteria, the cut-off level for IgE remains contentious. When the major and minor diagnostic criteria were suggested [73, 74], the proposed cut-off level was $1000 \mathrm{IU} \cdot \mathrm{mL}^{-1}\left(\sim 2500 \mathrm{ng} \cdot \mathrm{mL}^{-1}\right)$. However, as per the minimal essential criteria [19], the serum IgE level required for establishing the diagnosis was reduced to $417 \mathrm{IU} \cdot \mathrm{mL}^{-1}$ $\left(1000 \mathrm{ng} \cdot \mathrm{mL}^{-1}\right)$. Patients with AIA and SAFS without ABPA also exhibit a wide range of elevated $\operatorname{IgE}$ levels. According to the ABPA in CF consensus criteria, serum $\mathrm{IgE}>500 \mathrm{IU} \cdot \mathrm{mL}^{-1}$ is considered diagnostic [62]. The ISHAM working group has proposed a cut-off level of $1000 \mathrm{IU} \cdot \mathrm{mL}^{-1}$ [68], as they "felt that a cutoff of $500 \mathrm{IU} \cdot \mathrm{mL}^{-1}$ may lead to over diagnosis of ABPA". This value needs global validation as it could possibly be affected by ethnicity and exposure risk.

\section{Specific $\lg E / \lg G$ to A. fumigatus}

Detection of sufficiently high levels of serum IgE and IgG antibodies specific to A. fumigatus is also one of the minimal essential criteria that need to be fulfilled for the diagnosis of ABPA [19]. ELISA was initially used for estimation but was replaced by the radioimmunoassay method as low levels of IgE-A. fumigatus could not be detected by ELISA [124]. However, the radioimmunoassay technique also had drawbacks, such as short shelf-life of the radioisotope and exposure to radioactivity. Using the biotin avidin-linked immunosorbent assay method in 13 patients with ABPA, nine patients with AIA, 12 with aspergilloma and nine controls without asthma, significantly higher IgE-A. fumigatus levels were found in patients with ABPA, even at very high dilutions of 1:1000 [125]. The authors postulated that this could be due to a polyclonal antibody response to Aspergillus antigens in patients with ABPA, which is not seen in AIA. As mentioned in the minimal essential criteria for diagnosis, the serum values of IgE- and IgG-A. fumigatus in patients with ABPA should be at least double the pooled serum samples of patients with AIA [59]. If values from the controls are not available for comparison, then, as suggested by the ISHAM working group, an IgE-A. fumigatus level $>0.35 \mathrm{kUA} \cdot \mathrm{L}^{-1}$ could be considered [68]. However, in an appropriate clinical setting, very high serum levels of IgE- or IgG-A. fumigatus may be diagnostic of ABPA $[59,74]$. Using recombinant A. fumigatus allergens, ABPA can be distinguished from AIA with high specificity $(100 \%)$ and sensitivity (90\%) [126]. Exclusivity of rAsp f 2 for ABPA has also been documented [127]. In patients with CF, high levels of specific IgE to recombinant A. fumigatus allergens helped in differentiating those with associated ABPA from the non-ABPA CF patients [128, 129].

It is now recognised that a subset of patients with ABPA present either at an earlier stage of the disease or with a milder form. In these patients, central bronchiectasis is not present but other diagnostic criteria are fulfilled [77, 130]. Such serologically positive patients who meet all other ABPA criteria except central bronchiectasis, are categorised as serological ABPA and treatment can be initiated to avoid further chronic lung damage. In the presence of central bronchiectasis, the patient is labelled as ABPA-central bronchiectasis [130]. In order to correlate the severity of central bronchiectasis on high-resolution CT, it was observed that eosinophils and neutrophils in induced sputum were higher in patients with ABPA-central bronchiectasis compared to those with serological ABPA [131]. 
Precipitating antibodies against A. fumigatus

Precipitating antibodies against A. fumigatus, as demonstrated by the double immunodiffusion technique of OutCHERLONY [132], can be detected in the unconcentrated serum of $70 \%$ of patients [89]. When the serum is concentrated, these antibodies can be detected in $92 \%$ of patients with a radiological infiltrate [89]. These precipitating antibodies may also be present in $10 \%$ of asthmatics who do not have ABPA [7]. High levels of serum precipitins against $A$. fumigatus have also been shown in various other forms of chronic pulmonary aspergillosis [133]. High titres in patients with ABPA could imply the presence of complicating features such as fibrosis and cavitation [134].

Sputum examination

In patients with productive cough, sputum eosinophilia is often present and fungal hyphae may be demonstrated on sputum smear examination. The presence of plugs in the sputum, coinciding with acute febrile illness, was noted in two of the three patients in the first report of ABPA by HINSON et al. [3]. In addition, sputum culture for $A$. fumigatus was positive in all three patients. Over the years, expectoration of golden-brownish sputum plugs has been noted in up to $56 \%$ of patients with ABPA [89, 91], whilst sputum culture yielded Aspergillus species in $\sim 58 \%$ of cases [89]. Repeated growth of Aspergillus in the sputum of a patient with AIA should increase the suspicion of ABPA. However, the specificity of sputum testing for ABPA is not very high and, as such, is categorised under the minor criteria for diagnosis.

Detectable A. fumigatus DNA in the sputa of patients with ABPA, in whom routine cultures for Aspergillus were negative, was also observed [135]. There is a role for sputum analysis in monitoring the severity of disease and in determining the course of the illness. As mentioned previously, higher levels of sputum eosinophilia and neutrophilia were found in patients with ABPA-central bronchiectasis when compared with serological ABPA [131]. Sputum cultures and molecular testing may also help in assessing the response to antifungal therapy, as well as in identifying drug resistance to azoles.

\section{Pulmonary function testing}

Pulmonary function testing in ABPA does not help the pulmonologist to assess the severity or the extent of the disease. During the remission stage, even in the presence of bronchiectasis, the lung volumes and flow rates could be normal if the asthma is well controlled. An obstructive airflow pattern is most commonly found during an acute episode or an exacerbation. Nevertheless, a restrictive pattern along with reduction in total lung capacity and impaired diffusion capacity of the lung for carbon monoxide may also be seen. Varying degrees of obstruction are noted in patients in the corticosteroid-dependent stage. When the disease progresses to the chronic fibrotic stage, the pulmonary function testing typically shows an irreversible mixed pattern characterised by airflow obstruction, reduced lung volumes and low diffusion capacity [136]. Apart from obstructive airways disease, restriction, as well as a mixed pattern, has also been observed in either the acute or exacerbation stages (stages 1 and 3) of ABPA [137]. The forced expiratory volume in $1 \mathrm{~s}$ (FEV1), FEV1/forced vital capacity ratio and forced expiratory flow of $25-75 \%$ of forced vital capacity were significantly $(\mathrm{p}<0.05)$ reduced in patients with a mean duration of illness $>10$ years. A reduced diffusing capacity was also found in almost half of the patients tested.

\section{Staging}

Conventionally, five stages of ABPA were identified [138, 139]: 1) acute, 2) remission, 3) exacerbation, 4) corticosteroid-dependent asthma, and 5) fibrotic lung disease. Staging of the disease should be done at the time of diagnosis and re-evaluated periodically. In patients with acute disease (stage 1), remission (stage 2) may occur either spontaneously or may be induced by treatment. Although very few patients remain in remission for prolonged periods, exacerbation after prolonged remission was seen in a patient with ABPA and an associated aspergilloma [140]. It is sometimes difficult to taper off oral corticosteroids in stage 1 patients and these patients could progress directly to the corticosteroid-dependent stage (stage 4). This stage can be difficult to distinguish from corticosteroid-dependent asthma without ABPA [141]. Patients with a longstanding illness along with extensive bronchiectasis develop end-stage lung fibrosis (stage 5) and may present with respiratory failure. Fibrotic lung disease in stage 5 ABPA may be associated with clubbing and cavitation [85], and is often difficult to differentiate from fibrocavitary disease caused by tuberculosis [109, 110].

The ISHAM working group has proposed a new clinical staging of ABPA in asthma [68]. Stage 0, added prior to stage 1 , includes clinically stable and well-controlled asthmatic subjects who do not have any clinical features suggestive of ABPA but are diagnosed as ABPA when routinely investigated as per the criteria. This would be helpful in recognising the disease at the initial stage, which would enable commencement of appropriate treatment at the earliest and possibly prevent progression to the fibrotic stage. Stage 1 has been subclassified as 1a (with mucoid impaction, as documented on imaging or bronchoscopy) and $1 \mathrm{~b}$ (without mucoid impaction). A patient is said to be in stage 2 (response) when 
there is clinico-radiological improvement and at least a $25 \%$ decline in serum IgE level at 8 weeks of therapy. Stage 3 (exacerbation) occurs after clinical and/or radiological worsening is associated with an increase in IgE level by $>50 \%$ of baseline. Stage 4 (remission) is defined when there is sustained clinicoradiological improvement along with baseline IgE values (or $<50 \%$ increase) for $>6$ months duration without systemic corticosteroids. Stage 5 has been subclassified into 5a (treatment dependent ABPA, where frequent courses of corticosteroids or azoles are required for controlling the activity of ABPA) and $5 \mathrm{~b}$ (steroid dependent asthma, where systemic steroids are required for control of asthma whilst activity of ABPA is under control). In stage 6, the patient has advanced disease with radiological features of fibrosis along with clinical signs of cor pulmonale and type 2 respiratory failure. However, this newly proposed stage would require validation.

Radiological staging

Based on thoracic CT findings, the ISHAM working group has proposed a new radiological classification of ABPA [68]. The purpose of this classification scheme is to correlate the immunological severity of the disease with various radiological features. The presence of HAM has previously been demonstrated to be associated with increased levels of IgE-A. fumigatus [142]. The four major categories proposed by the ISHAM working group, as the disease progresses from mild to moderate to severe, include [68]: 1) serological ABPA, 2) ABPA with bronchiectasis, 3) ABPA with HAM, and 4) ABPA with chronic pleuropulmonary fibrosis. In order to be classified as ABPA-chronic pleuropulmonary fibrosis, at least two other findings, apart from bronchiectasis and HAM, such as pulmonary fibrosis, parenchymal scarring, fibrocavitary lesions, aspergilloma and pleural thickening should be present.

\section{Treatment}

The goals of therapy for ABPA include [61]: 1) detection and prompt treatment of exacerbations in order to prevent or minimise the development of central bronchiectasis; 2) management of underlying asthma (stages 1 to 4 ) or irreversible lung disease (stage 5); 3) exclusion of ABPA among family members; and 4) identification of any potential environmental source of the incriminated fungus. The treatment provided should aim at achieving remission in order to avoid further lung damage. Moreover, the drugs prescribed should have the least possible adverse effects. To date, there are no well-designed clinical trials for pharmacological intervention in ABPA. Systemic glucocorticoids and antifungal agents are the two main group of drugs studied to date. The usage of inhaled corticosteroids alone may only help to achieve asthma control but would not prevent symptomatic exacerbations.

\section{Glucocorticoids}

Oral corticosteroids are the mainstay for the treatment of ABPA [143]. In view of their anti-inflammatory properties, they aid in suppressing the immune hyperreactivity that is present in patients with asthma and ABPA. Steroids also decrease sputum production and inhibit the toxic antigen-antibody reaction between the fungi and the host, thereby rendering the bronchi less hospitable for Aspergillus. Various glucocorticoid regimens incorporating different doses and duration of therapy have been advocated for the management of ABPA. In patients with stages 1 (acute) and 3 (exacerbation) of the disease, the most widely advocated steroid protocol is prednisolone $\left(0.5 \mathrm{mg} \cdot \mathrm{kg}^{-1} \cdot \mathrm{day}^{-1}\right.$ for the first 2 weeks followed by $0.5 \mathrm{mg} \cdot \mathrm{kg}^{-1} \cdot \mathrm{day}^{-1}$ on alternate days for the next 2 months) [59]. Once decline in the total serum $\operatorname{IgE}$ level $>35 \%$ is achieved, the dosage can be tapered off by $2.5 \mathrm{mg}$ every 2 weeks [144]. Stage 4 ABPA patients are managed with 10-40 mg prednisolone on alternate days for many years as repeated attempts to discontinue may result in unacceptable wheezing. If prednisolone can be discontinued, the patient should initially be evaluated every 6-8 weeks to help determine whether remission (stage 2) is maintained. Stage 5 patients may require daily prednisolone along with therapy for cor pulmonale and hypoxaemia [61, 145].

In order to shorten the duration of corticosteroid therapy, a higher initial dosage of prednisolone, $0.75 \mathrm{mg} \cdot \mathrm{kg}^{-1} \cdot \mathrm{day}^{-1}$ for the initial 6 weeks that was subsequently tapered off, was tried. This was associated with higher remission rates and less chances of progressing to the steroid-dependent stage [146, 147]. In one of the older case series wherein oral corticosteroids were prescribed for only 3 months duration [77], approximately half of the patients also progressed to the steroid-dependent stage. The aggressive higher initial corticosteroid regimen advocated by some authors to obtain "the best long-term outcomes" currently appears to have limited documentary support [148]. The findings of a randomised controlled trial on the efficacy and safety of two different corticosteroid regimens in ABPA are awaited (www.clinicaltrials.gov identifier number NCT00974766).

Since oral prednisolone needs to be prescribed for long durations, the feasibility of a biweekly dosing schedule was assessed in 26 patients with ABPA with or without AAS [149]. After the initial daily dosage for 2 weeks, patients were alternately prescribed either the conventional alternate day tapering regimen or a 
twice weekly dosing schedule. A significant improvement in FEV1, total IgE levels and eosinophil counts was noted in patients receiving the biweekly regimen. This may possibly help in reducing the well-known adverse effects of long-term corticosteroid therapy. Several studies in children with ABPA and CF have demonstrated the usefulness of intravenous pulse methylprednisolone therapy for the management of severe, and sometimes life-threatening, exacerbations [150-152].

\section{Antifungal agents}

The role of antifungal agents in the treatment of ABPA is not fully determined. By reducing the fungal burden, this group of drugs helps in suppressing the inflammatory response by mitigating the antigenic stimulus [153]. All-in-all, this would minimise the need for corticosteroid therapy [154]. In the initial studies, older antifungal molecules including natamycin, hamycin, amphotericin B, miconazole, clotrimazole and ketoconazole were used but were either ineffective or exhibited adverse reactions.

Subsequently, the focus of attention has been on itraconazole, a less toxic and more active drug, with two randomised double-blind trials being published to date $[155,156]$. In the first study, patients with steroid dependent (stage 4) ABPA were administered either itraconazole $200 \mathrm{mg}$ twice daily or placebo over 16 weeks [155]. Patient in the study group demonstrated lower total IgE levels, improved lung function parameters, increased exercise tolerance and, most importantly, a decrease in the dosage of oral corticosteroids. In the second study, which included "clinically stable" patients, concurrent itraconazole usage of $400 \mathrm{mg}$ daily or placebo for 16 weeks resulted in a significant decline in sputum inflammatory markers and serum IgE levels [156]. Both these trials were short term since relapse of ABPA beyond 8 months was not assessed in either study. WARK [26] then concluded that "itraconazole improves shortterm symptoms and reduces the frequency of exacerbations that require the use of oral corticosteroids". The author also cautioned that the drug "may exacerbate the adrenal suppression seen with regular corticosteroids use". Periodic itraconazole blood levels should be monitored for ensuring adequate bioavailability as lower than therapeutic levels may result in clinical failure and possible development of drug resistance [157, 158]. Resistance to both itraconazole and voriconazole along with reduced susceptibility to posaconazole was documented in a patient with ABPA previously exposed to itraconazole. The patient responded to high-dose posaconazole [159].

Until further information from large randomised, double-blind, placebo-controlled, parallel, long-term studies is available, the use of itraconazole alone should be restricted to patients in whom oral corticosteroids are absolutely contraindicated. Itraconazole may be added in patients experiencing recurrent exacerbations despite adequate steroid therapy. The role of itraconazole monotherapy for ABPA is still not established. Currently, a randomised trial on monotherapy of itraconazole versus prednisolone in ABPA is underway (www.clinicaltrials.gov identifier NCT01321827). Voriconazole and posaconazole, two newer azoles, have also been tried in patients with ABPA [160-164]. However, serious adverse effects such as skin cancer were associated with long-term voriconazole therapy [165].

\section{Omalizumab}

In the past, the role of omalizumab, a monoclonal antibody against IgE, has been investigated for the treatment of ABPA. Most of the initial studies were in patients with underlying CF [166-168]. The results were encouraging as there was a significant improvement in symptoms, pulmonary functions, hospitalisation episodes and exacerbation rates. In addition, a reduction in the usage of oral corticosteroids was noted. Recent studies in patients with ABPA due to underlying asthma also demonstrated statistically significant symptom control, reduction in eosinophilia and total IgE levels, improved FEV1, fewer asthma exacerbations and decreased usage of oral corticosteroids after appropriate therapy with omalizumab [169-171]. This drug could possibly have the potential to emerge as a steroid-sparing alternative in a select subset of patients who continue to remain corticosteroid dependent (stage 4). Since there are no randomised studies performed to date with omalizumab, routine usage in ABPA is not yet recommended. Currently, it is being prescribed in patients with CF who have corticosteroid dependence or in those with adverse reactions to steroid therapy.

\section{ABPA and CF}

Other than asthma, ABPA can also occur in CF. Atopy is the main risk factor for ABPA in patients with CF [172]. The mucous present within the bronchi provides a favourable environment for the germination of inhaled Aspergillus spores. The prevalence of ABPA in CF is not truly defined and this could be as high as $25 \%$ [173]. This discrepancy has been attributed to the lack of uniform diagnostic criteria, which is due to the remarkable similarities in the clinical presentations and chest radiograph appearances in CF and ABPA patients. However, the presence of central bronchiectasis with normal peripheral bronchi, the key diagnostic 
component in ABPA, is not helpful in diagnosing ABPA in patients with $\mathrm{CF}$. In contrast to ABPA, bronchiectasis also extends to the periphery in $\mathrm{CF}$.

A large database from the Epidemiologic Study of Cystic Fibrosis (ESCF), conducted in the USA and Canada, was used to estimate the prevalence of ABPA in patients with CF [174]. The ESCF criteria adopted for the diagnosis of $\mathrm{ABPA}$ in $\mathrm{CF}$ included the presence of two of the following: 1) immediate skin reactivity to A. fumigatus antigens, 2) precipitating antibodies to A. fumigatus antigens, and 3) total serum $\operatorname{IgE}$ $>1000 \mathrm{IU} \cdot \mathrm{mL}^{-1}$; and at least two of the following: 1) bronchoconstriction, 2) peripheral blood eosinophilia $>1000$ cells $\left.\cdot \mu \mathrm{L}^{-1}, 3\right)$ history of pulmonary infiltrates, 4) elevated specific IgE-/IgG-A. fumigatus, 5) A. fumigatus in sputum by smear or culture, and 6) response to steroids. Based on this, the overall reported prevalence of ABPA in CF was found to be $2 \%$. In a subsequent study from Europe [173], based on analysis of Epidemiologic Registry of Cystic Fibrosis (ERCF) data from nine countries, the overall prevalence of ABPA in the ERCF population was $7.8 \%$. A validated set of criteria for the diagnosis of ABPA in CF is yet to be established and the suspicion of ABPA in patients with CF is based on the collection of clinical, radiological and immunological parameters.

Treatment for ABPA remains the same in patients with $\mathrm{CF}$ as they also respond to oral corticosteroids. However, the adverse effects of oral steroids such as steroid-induced diabetes, osteoporosis and pathological fractures may be exaggerated in these patients. This makes the management of ABPA in patients with CF difficult. Itraconazole as a steroid-sparing agent has been well tolerated in patients without underlying liver disease, leading to a 50\% reduction in the average oral steroid dose [172]. Omalizumab also has been shown to help in decreasing the requirement of corticosteroids in this group of patients [166-168].

\section{ABPA in chronic obstructive pulmonary disease and other respiratory disorders}

Apart from asthma, ABPA has also been documented in patients with chronic obstructive pulmonary disease (COPD) $[175,176]$. In addition, single case reports of ABPA associated with other lung diseases including chronic granulomatous disease and hyper-IgE syndrome [177] and Kartagener's syndrome [178] have been published.

The disease processes in asthma and COPD are somewhat similar. As proposed in the Dutch hypothesis, the development of either asthma or COPD would depend on the modulation of host factors by various environmental stimuli. Increased bronchial hyperreactivity [179], elevated total IgE levels [180] and peripheral eosinophilia [181] have been demonstrated in smokers. A subset of patients with COPD exists in whom eosinophilic inflammation of the airways, impaired mucociliary clearance and mucus hypersecretion is found [182, 183]. This could potentially lead to increased Aspergillus colonisation and subsequent development of ABPA in COPD [176]. In 200 patients with COPD, Aspergillus sensitisation was documented in $8.5 \%$ and only two (1\%) patients had serological ABPA [175]. The rarity of the association of ABPA and COPD could possibly be due to differences in the nature of airway inflammation in COPD and asthma, as well as differences in the genetic predisposition [176]. Further studies are warranted to determine the frequency of ABPA in COPD.

\section{Allergic bronchopulmonary mycoses}

Some patients present with bronchial asthma, a history of expectoration of sputum plugs, fleeting shadows on serial chest radiographs, peripheral blood eosinophilia and increased total IgE but with negative skinprick/intradermal and serologic tests for Aspergillus. This syndrome, akin to ABPA, is caused by fungi other than Aspergillus and is collectively known as ABPM [184]. Sputum examination usually provides the first clue. The diagnosis is established according to the Rosenberg-Patterson criteria $[73,74]$ as stated in a recent review on ABPM [185]. To date, more than 26 different fungi have been shown to cause ABPM [184]. The common fungi are Candida albicans, Bipolaris, Schizophyllum commune, Curvularia lunata, Penicillium, Dreschlera hawaiiensis, Pseudoallescheria boydii, Alternaria alternata, Fusarium vasinfectum, Rhizopus oryzae, Geotrichum candidum and Stemphylium lanuginosum [184, 185].

It may be difficult, without the facilities of a research laboratory, to prove the fungus responsible for ABPM. When features suggestive of ABPA are present, in particular central bronchiectasis, ABPM should be suspected and oral corticosteroids should be considered as ABPM responds well to the therapy. This is a prudent approach as ABPM, if left untreated, can lead to progressive and irreversible lung damage [184].

\section{ABPA and other Aspergillus-related disorders}

The clinical categories of Aspergillus-related respiratory disorders usually remain mutually exclusive. There is an overlapping disease mechanism in ABPA and AAS as both the entities are characterised by an IgEmediated inflammatory response to Aspergillus antigens. However, concurrent ABPA and AAS have not often been reported $[24,101,113,186]$. The coexistence of ABPA with an aspergilloma is also infrequently 
described [109, 110, 187]. The association of ABPA, AAS and aspergilloma in the same patient has been documented to date only twice $[113,188]$.

\section{Allergic Aspergillus sinusitis}

In AAS, mucoid impaction akin to that in ABPA occurs in the paranasal sinuses $[189,190]$. The first case of AAS, as a separate clinical entity, was published in 1981 [191]. Inhalation of Aspergillus spores via the sinonasal route leads to the release of antigenic material, which in turn sets into motion a similar chain of immunological reactions as encountered in the bronchi of patients with ABPA. Why the incriminating fungus has a predilection for the sinuses in some patients and the bronchi in others is still unknown. It has previously been reported that a quarter of patients with perennial rhinitis were sensitised to Aspergillus antigens [192], and rhinitis is an important risk factor for sinusitis. Furthermore, sensitisation to Aspergillus antigens increased the severity of sinusitis in patients with allergic rhinitis [193]. It is quite possible that patients with Aspergillus-sensitised rhinitis could be at a greater risk of developing AAS. When fungi other than Aspergillus are involved, the disease is labelled as allergic fungal sinusitis (AFS). Other fungi implicated in AFS include Alternaria, Curvularia, Bipolaris, Exserohilum, Drechslera and Cladosporium [194-197].

As in ABPA, a set of criteria is required for the diagnosis of AAS (table 4). The key feature is the presence of allergic mucin, which is the characteristic nasal pathological material comprising eosinophils, CharcotLeyden crystals, cellular debris and scattered fungal hyphae [186]. Amongst the radiological modalities, CT is the gold standard for evaluation. The hallmark finding is the presence of heterogeneous densities, signifying opacification of the sinuses, with serpiginous areas of increased attenuation (fig. 6) on noncontrast scans $[98,198]$. These hyperdense areas are due to calcium in the allergic mucin. Although there is no standard protocol for treating AAS/AFS, it appears prudent to adopt a combined approach with pharmacological therapy and surgical intervention [186, 199].

The first report of AAS with concurrent ABPA was published in 1988 [200] and several more cases have been reported since [24, 25, 101, 113, 186, 188, 201-204]. In a review of 95 patients with ABPA [186], radiological evidence of sinusitis was present in 22 patients. Concomitant AAS was diagnosed in seven out of nine patients who consented to the invasive procedures required to obtain histopathological specimens from the sinuses. However, the possibility of AAS could not be ruled out in the remaining 13 patients as they refused to undergo the surgery needed in order to establish the diagnosis. Hypothetically, the frequency of AAS among patients with ABPA could be higher.

To highlight the expression of fungal hypersensitivity in both upper and lower airways, VENARSKE and DESHAZO [202] coined the term "sinobronchial allergic mycosis" (the SAM syndrome). This description was based on five patients, three of whom were previously reported for their unusual presentations [24, 101, 113]. The authors further stated in the addendum that the other four cases of concomitant ABPA and AAS also fulfilled the criteria for SAM syndrome [186]. Three out of four pairs of patients with familial ABPA had concomitant AAS [25]. Among these eight patients, seven had symptoms suggestive of allergic rhinitis. Sinusitis on CT was demonstrated in four out of the seven, three of whom were finally diagnosed with concominant AAS.

Since asthma and sinusitis are often seen by two different specialties, the occurrence of AAS in ABPA and of ABPA in AAS may easily be overlooked $[186,205]$. There was no mention of concomitant ABPA in a series of 44 patients with AFS from the Mayo Clinic (Rochester, MN, USA) [206]. In another study of 67 consecutive cases of AFS predominantly caused by Bipolaris spicifera, concomitant AFS and ABPM were only seen in two patients [197]. In an analysis of 155 patients with ABPA from northern India, there was no mention of nasal symptoms [69]. Amongst the paediatric age group, asthma was identified in 20 children with fungal sinusitis but these were not investigated further for the presence of ABPA [207].

\section{Aspergilloma}

Fungal balls due to Aspergillus species, also known as aspergilloma, usually develop in pre-existing cavities, most commonly seen in healed tuberculosis, over a period ranging from a few months to $>10$ years [208]. Chronic lung damage in ABPA could quite possibly favour the development of an aspergilloma. This would be more evident when cavity formation is present in ABPA. Aspergillomas may appear either prior to or after the onset of ABPA. However, for reasons that are unknown, the concomitant occurrence of these two entities remains uncommon.

In patients with coexistent $\mathrm{ABPA}$ and aspergilloma $[109,110,113,187,188]$, the fungal balls formed in preexisting cavities many years after the diagnosis of ABPA. Moreover, corticosteroid therapy could hasten the development of an aspergilloma in patients with cavitary lung disease [109, 187]. The occurrence of ABPA in a patient with an aspergilloma has also been documented previously $[209,210]$. The presence of an 
TABLE 4 Diagnostic criteria for allergic Aspergillus sinusitis [186, 189]

\section{Sinusitis of one or more paranasal sinus on radiography}

Necrosed amorphous tissue along with oedematous polyps infiltrated with eosinophils on histopathological evaluation of material from the sinus Demonstration of fungal elements in nasal discharge or in material obtained at the time of surgery by stain or culture Absence of diabetes, previous or subsequent immunodeficiency disease, and treatment with immunosuppressive drugs Absence of invasive fungal disease at the time of diagnosis or subsequently

\section{Other features}

Peripheral blood eosinophilia

Type I and type III cutaneous hypersensitivity to Aspergillus

Precipitating antibodies to Aspergillus antigens

Elevated total, as well as Aspergillus-specific, IgE levels

Characteristic computed tomography appearances

aspergilloma may function as a nidus for antigenic stimulation in a genetically predisposed individual [210]. In 1973, MCCARTHY and PEPYs [209] postulated that patients with aspergilloma could possibly have been sensitised to Aspergillus antigens, which in turn may lead to the development of ABPA. Multiple aspergillomas within multifocal lung parenchymal cavities have also been reported in patients with ABPA [109, 211]. Pendleton and Denning [211] have recently stated that, in patients with ABPA, associated multiple aspergillomas is a rare form of chronic pulmonary aspergillosis.

Managing such patients is a challenge to the clinician as steroid therapy could aggravate the underlying condition, especially in the presence of a pre-existing cavitary disease. The formation of aspergilloma occurred after the initiation of corticosteroid treatment in two published cases with concurrent ABPA and aspergilloma [109, 187]. One of these patients developed an exacerbation of ABPA after being in the remission stage for 3 years [140]. Usage of antifungal agents could help in reducing both the dosage of corticosteroids, as well as decreasing the fungal load in the airways. We had hypothesised that the presence of an aspergilloma in a patient with ABPA was likely to increase the severity of the disease [212]. Recently, AgARWAL et al. [213] lent support to our hypothesis by demonstrating recurrent relapses in their group of patients with coexistent ABPA and aspergilloma. All patients with ABPA and cavitation should be closely monitored when initiated on corticosteroids.

\section{ABPA, AAS and aspergilloma}

The association of ABPA, AAS and aspergilloma in the same patient has only been documented twice to date $[113,188]$. The first patient had undergone a left lower lobectomy for severe haemoptysis, the cause of which was found to be an aspergilloma in a bronchiectatic cavity [113]. She was subsequently diagnosed as a case of ABPA and AAS when she presented with left pleural effusion and associated underlying collapse of

FIGURE 6 Computed tomography of the paranasal sinuses showing hyperdense lesions in the frontal, ethmoid and maxillary sinuses bilaterally, suggestive of inspissated secretions.

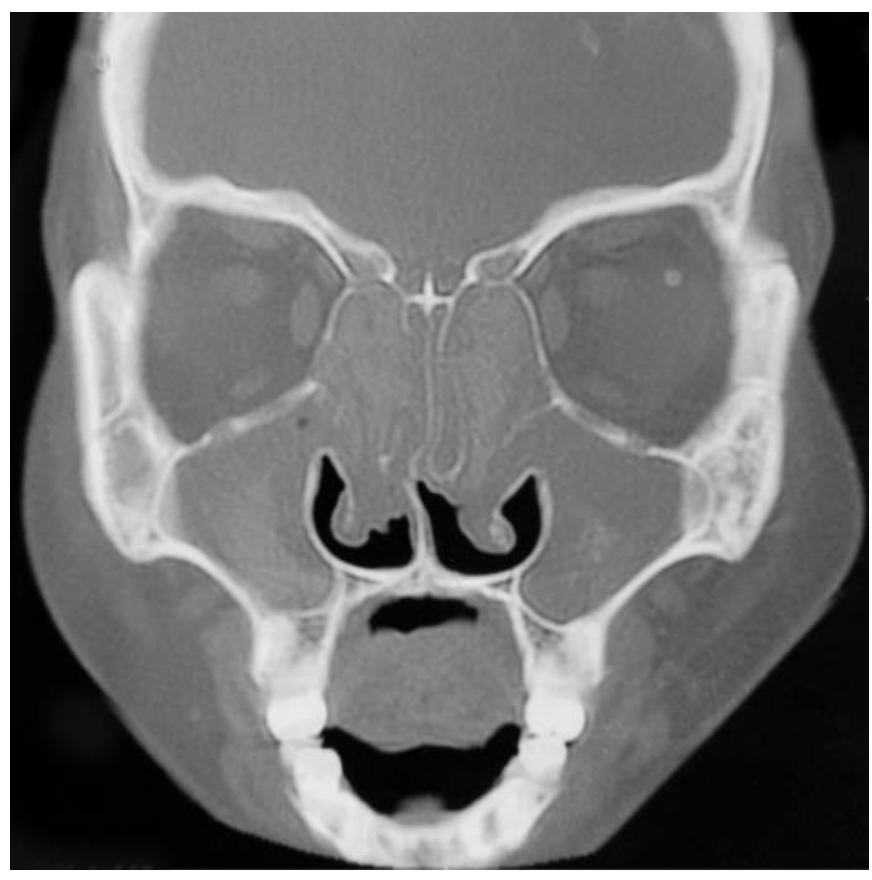


the left lung. In the second patient, all three clinical entities were diagnosed concurrently when he presented for evaluation of progressive respiratory symptoms [188]. In this patient, the aspergilloma disappeared after maintenance therapy with repeated courses of oral prednisolone.

\section{Conclusions}

In high tuberculous prevalence areas, patients with ABPA are often mistakenly diagnosed as having tuberculosis due to the radiological similarities. Such patients are often mistreated for a long duration while lung damage continues to progress silently. A patient walking into the pulmonology clinic with numerous chest radiographs and peripheral eosinophilia along with a history suggestive of asthma should always be investigated for ABPA. In essence, ABPA must be looked for in all asthmatics with positive skin sensitivity to Aspergillus antigens $[8,214]$ and must also be excluded in patients with COPD $[175,176]$. In developing countries, CT scans remain expensive and laboratory investigations including mycology and Aspergillusspecific serology testing are not widely available. Often this delays diagnosis, thereby resulting in increased morbidity. Initiation of appropriate therapy could alter the natural course of the disease and prevent endstage lung fibrosis [61]. Furthermore, the occurrence of AAS in ABPA and ABPA in AAS should always be investigated $[186,215]$.

\section{References}

Shah A. Allergic bronchopulmonary aspergillosis. Indian J Chest Dis Allied Sci 1998; 40: 41-54.

de Shazo RD, Chapin K, Swain RE. Fungal sinusitis. N Engl J Med 1997; 337: 254-259.

Hinson KFW, Moon AJ, Plummer NS. Bronchopulmonary aspergillosis: a review and a report of eight new cases. Thorax 1952; 7: 317-333.

4 Shah A, Panjabi C. Allergic bronchopulmonary aspergillosis: a review of a disease with a worldwide distribution. J Asthma 2002; 39: 273-289.

5 Longbottom JL, Pepys J. Pulmonary aspergillosis, diagnostic and immunological significance of antigens and Creactive substance in Aspergillus fumigatus. J Pathol Bacteriol 1964; 88: 141-151.

6 Hendrick DJ, Davies RJ, D'Souza MF, et al. An analysis of skin prick test reactions in 656 asthmatic patients. Thorax 1975; 30: 2-8.

7 Schwartz HJ, Citron KM, Chester EH, et al. A comparison of the prevalence of sensitization to Aspergillus antigens among asthmatics in Cleveland and London. J Allergy Clin Immunol 1978; 62: 9-14.

8 Maurya V, Gugnani SC, Sarma PU, et al. Sensitization to Aspergillus antigens and occurrence of allergic bronchopulmonary aspergillosis in patients with asthma. Chest 2005; 127: 1252-1259.

9 Fairs A, Agbetile J, Hargadon B, et al. IgE sensitisation to Aspergillus fumigatus is sssociated with reduced lung function in asthma. Am J Respir Crit Care Med 2010; 182: 1362-1368.

10 Menzies D, Holmes L, McCumesky G, et al. Aspergillus sensitization is associated with airflow limitation and bronchiectasis in severe asthma. Allergy 2011; 66: 679-685.

11 Agarwal R, Noel V, Aggarwal AN, et al. Clinical significance of Aspergillus sensitisation in bronchial asthma. Mycoses 2011; 54: e531-e538.

12 Agbetile J, Fairs A, Desai D, et al. Isolation of filamentous fungi from sputum in asthma is associated with reduced post-bronchodilator FEV1. Clin Exp Allergy 2012; 42: 782-791.

13 Zureik M, Neukirch C, Leynaert B, et al. Sensitisation to airborne moulds and severity of asthma: cross sectional study from European Community respiratory health survey. Br Med J 2002; 325: 411-414.

14 Kauffman HF, van der Heide S. Exposure, sensitization, and mechanisms of fungus-induced asthma. Curr Allergy Asthma Rep 2003; 3: 430-437.

15 Denning DW, O'Driscoll BR, Hogaboam CM, et al. The link between fungi and severe asthma: a summary of the evidence. Eur Respir J 2006; 27: 615-626.

16 Denning DW, O'Driscoll BR, Powell G, et al. Randomized controlled trial of oral antifungal treatment for severe asthma with fungal sensitization: the Fungal Asthma Sensitization Trial (FAST) study. Am J Respir Crit Care Med 2009; 179: 11-18.

17 Pasqualotto AC, Powell G, Niven R, et al. The effects of antifungal therapy on severe asthma with fungal sensitization and allergic bronchopulmonary aspergillosis. Respirology 2009; 14: 1121-1127.

18 Greenberger PA. When to suspect and work up allergic bronchopulmonary aspergillosis. Ann Allergy Asthma Immunol 2013; 111: 1-4.

19 Greenberger PA. Allergic bronchopulmonary aspergillosis. I Allergy Clin Immunol 2002; 110: 685-692.

20 Patterson R. Allergic bronchopulmonary aspergillosis and hypersensitivity reactions to fungi. In: Fishman AP, Elias JA, Fishman JA, et al., eds. Fishman's Pulmonary Diseases and Disorders. 3rd Edn. Vol. 1. New York, McGraw-Hill \& Co., 1998; pp. 777-782.

21 Kramer MN, Kurup VP, Fink JN. Allergic bronchopulmonaty aspergillosis from a contaminated dump site. Am Rev Respir Dis 1989; 140: 1086-1088.

22 Allmers H, Huber H, Baur X. Two year follow-up of a garbage collector with allergic bronchopulmonary aspergillosis (ABPA). Am J Ind Med 2000; 37: 438-442.

23 Graves TS, Fink JN, Patterson R, et al. A familial occurrence of allergic bronchopulmonary aspergillosis. Ann Intern Med 1979; 91: 378-382.

24 Shah A, Khan ZU, Chaturvedi S, et al. Concurrent allergic Aspergillus sinusitis and allergic bronchopulmonary aspergillosis associated with familial occurrence of allergic bronchopulmonary aspergillosis. Ann Allergy 1990; 64: 507-512.

25 Shah A, Kala J, Sahay S, et al. Frequency of familial occurrence in 164 patients with allergic bronchopulmonary aspergillosis. Ann Allergy Asthma Immunol 2008; 101: 363-369. 
26 Wark P. Pathogenesis of allergic bronchopulmonary aspergillosis and an evidence-based review of azoles in treatment. Respir Med 2004; 98: 915-923.

27 Bhatnagar PK, Banerjee B, Shah A, et al. Probable role of IgG subclasses in patients with allergic bronchopulmonary aspergillosis. Serodiagn Immunother Infect Dis 1993; 5: 123-124.

28 Kurup VP. Immunology of allergic bronchopulmonary aspergillosis. Indian J Chest Dis Allied Sci 2000; $42: 225-237$.

29 Kauffman HF, Tomee JFC, Vander Werf TS, et al. Review of fungus induced asthmatic reactions. Am J Respir Crit Care Med 1995; 151: 2109-2116.

30 Wark PAB, Gibson PG. Allergic bronchopulmonary aspergillosis: new concepts of pathogenesis and treatment. Respirology 2001; 6: 1-7.

31 Madan T, Banerjee B, Bhatnagar PK, et al. Identification of $45 \mathrm{kD}$ antigen in immune complexes of patients of allergic bronchopulmonary aspergillosis. Mol Cell Biochem 1997; 166: 111-116.

32 Purkayastha S, Madan T, Shah A, et al. Multifunctional antigens of Aspergillus fumigatus and specific antibodies. Appl Biochem Biotech 2000; 83: 271-286.

33 Chauhan B, Knutsen A, Hutcheson PS, et al. T cell subsets, epitope mapping, and HLA-restriction in patients with allergic bronchopulmonary aspergillosis. J Clin Invest 1996; 97: 2324-2331.

34 Chauhan B, Santiago L, Kirschmann DA, et al. The association of HLADR alleles and T cell activation with allergic bronchopulmonary aspergillosis. J Immunol 1997; 159: 4072-4076.

35 Chauhan B, Santiago L, Hutcheson PS, et al. Evidence for the involvement of two different MHC class II regions in susceptibility or protection in allergic bronchopulmonary aspergillosis. J Allergy Clin Immunol 2000; 106: 723-729.

36 Miller PW, Hamosh A, Macek M Jr, et al. Cystic fibrosis transmembrane conductance regulator (CFTR) gene mutations in allergic bronchopulmonary aspergillosis. Am J Hum Genet 1996; 59: 45-51.

37 Marchand E, Verellen-Dumoulin C, Mairesse M, et al. Frequency of cystic fibrosis transmembrane conductance regulator gene mutations and 5T allele in patients with allergic bronchopulmonary aspergillosis. Chest 2001; 119: $762-767$.

38 Eaton TE, Weiner Miller P, Garrett JE, et al. Cystic fibrosis transmembrane conductance regulator gene mutations: do they play a role in the aetiology of allergic bronchopulmonary aspergillosis? Clin Exp Allergy 2002; 32: 756-761.

39 Lebecque P, Pepermans X, Marchand E, et al. ABPA in adulthood: a CFTR-related disorder. Thorax 2011; 66: 540-541.

40 de Almeida MB, Bussamra MH, Rodrigues JC. Allergic bronchopulmonary aspergillosis in paediatric cystic fibrosis patients. Paediatr Respir Rev 2006; 7: 67-72.

41 Madan T, Kishore U, Shah A, et al. Lung surfactant proteins A and D can inhibit specific IgE binding to the allergens of Aspergillus fumigatus and block allergen-induced histamine release from human basophils. Clin Exp Immunol 1997; 110: 241-249.

42 Madan T. Potential of lung surfactant proteins, SP-A and SP-D, and mannan binding lectin for therapy and genetic predisposition to allergic and invasive aspergillosis. Recent Pat Inflamm Allergy Drug Discov 2007; 1: $183-187$.

43 Saxena S, Madan T, Shah A, et al. Association of polymorphisms in the collagen region of SPA2 with increased levels of total IgE antibodies and eosinophilia in patients with allergic bronchopulmonary aspergillosis. J Allergy Clin Immunol 2003; 111: 1001-1007.

44 Vaid M, Kaur S, Sambatakou H, et al. Distinct alleles of mannose-binding lectin (MBL) and surfactant proteins A (SP-A) in patients with chronic cavitary pulmonary aspergillosis and allergic bronchopulmonary aspergillosis. Clin Chem Lab Med 2007; 45: 183-186.

45 Knutsen AP, Kariuki B, Consolino JD, et al. IL-4 alpha chain receptor (IL-4Ralpha) polymorphisms in allergic bronchopulmonary aspergillosis. Clin Mol Allergy 2006; 4: 3.

46 Brouard J, Knauer N, Boelle PY, et al. Influence of interleukin-10 on Aspergillus fumigatus infection in patients with cystic fibrosis. J Infect Dis 2005; 191: 1988-1991.

47 Sambatakou H, Pravica V, Hutchinson IV, et al. Cytokine profiling of pulmonary aspergillosis. Int J Immunogenet 2006; 33: 297-302.

48 Kaur S, Gupta VK, Shah A, et al. Plasma mannan-binding lectin levels and activity are increased in allergic patients. J Allergy Clin Immunol 2005; 116: 1381-1383.

49 Kaur S, Gupta VK, Shah A, et al. Elevated levels of mannan-binding leptin (MBL) and eosinophilia in patients of bronchial asthma with allergic rhinitis and allergic bronchopulmonary aspergillosis associate with a novel intronic polymorphism in MBL. Clin Exp Immunol 2006; 143: 414-419.

50 Carvalho A, Pasqualotto AC, Pitzurra L, et al. Polymorphisms in toll-like receptor genes and susceptibility to pulmonary aspergillosis. J Infect Dis 2008; 197: 618-621.

51 Madan T, Priyadarsiny P, Vaid M, et al. Use of a synthetic peptide epitope of Asp f 1, a major allergen or antigen of Aspergillus fumigatus, for improved immunodiagnosis of allergic bronchopulmonary aspergillosis. Clin Diagn Lab Immunol 2004; 11: 552-558.

52 Gautam P, Sundaram CS, Madan T, et al. Identification of novel allergens of Aspergillus fumigatus using immunoproteomics approach. Clin Exp Allergy 2007; 37: 1239-1249.

53 Shah A. Allergic bronchopulmonary aspergillosis: a view from India. Saudi Med J 2002; 23 : $1559-1561$.

54 Novey HS. Epidemiology of allergic bronchopulmonary aspergillosis. Immunol Allergy Clin North Am 1998; 18: 641-653.

55 Henderson AH, English MP, Vecht RJ. Pulmonary aspergillosis: a survey of its occurrence in patients with chronic lung disease and a discussion of the significance of diagnostic tests. Thorax 1968; 23: 513-518.

56 Adiseshan N, Simpson J, Gandevia B. The association of asthma with Aspergillus and other fungi. Aust N Z J Med 1971; 4: 385-391.

57 Patterson R, Golbert TM. Hypersensitivity disease of the lung. Univ Mich Med Cent J 1968; 34 : 8-11.

58 Greenberger PA, Patterson R. Allergic bronchopulmonary aspergillosis and the evaluation of the patient with asthma. J Allergy Clin Immunol 1988; 81: 646-650.

59 Schwartz HJ, Greenberger PA. The prevalence of allergic bronchopulmonary aspergillosis in patients with asthma, determined by serologic and radiologic criteria in patients at risk. J Lab Clin Med 1991; 117: 138-142.

60 Eaton T, Garrett J, Milne D, et al. Allergic bronchopulmonary aspergillosis in the asthma clinic: a prospective evaluation of CT in the diagnostic algorithm. Chest 2000; 118: 66-72. 
61 Greenberger PA. Allergic bronchopulmonary aspergillosis. In: Middleton E Jr, Reed CE, Ellis EF, et al., eds. Allergy: Principles and Practice. 5th Edn. St. Louis, CV Mosby Co, 1998; pp. 981-993.

62 Stevens DA, Moss RB, Kurup VP, et al. Allergic bronchopulmonary aspergillosis in cystic fibrosis - state of the art: Cystic Fibrosis Foundation Consensus Conference. Clin Infect Dis 2003; 37: Suppl. 3, S225-S264.

63 Denning DW, Pleuvry A, Cole DC. Global burden of allergic bronchopulmonary aspergillosis with asthma and its complication chronic pulmonary aspergillosis in adults. Med Mycol 2013; 51: 361-370.

64 Benatar SR, Keen GA, Du Toit Naude W. Aspergillus hypersensitivity in asthmatics in Cape Town. Clin Allergy 1980; 10: 285-291.

65 Donnelly SC, McLaughlin H, Bredin CP. Period prevalence of allergic bronchopulmonary mycosis in a regional hospital outpatient population in Ireland 1985-88. Ir J Med Sci 1991; 160: 288-290.

66 Al-Mobeireek AF, El-Rab Mogad, Al-Hedaithy SS, et al. Allergic bronchopulmonary mycosis in patients with asthma: period prevalence at a university hospital in Saudi Arabia. Respir Med 2001; 95: 341-347.

67 Ma YL, Zhang WB, Yu B, et al. Prevalence of allergic bronchopulmonary aspergillosis in Chinese patients with bronchial asthma. Zhonghua Jie He He Hu Xi Za Zhi 2011; 34: 909-913.

68 Agarwal R, Chakrabarti A, Shah A, et al. Allergic bronchopulmonary aspergillosis: review of literature and proposal of new diagnostic and classification criteria. Clin Exp Allergy 2013; 43: 850-873.

69 Agarwal R, Gupta D, Aggarwal AN, et al. Clinical significance of hyperattenuating mucoid impaction in allergic bronchopulmonary aspergillosis: an analysis of 155 patients. Chest 2007; 132: 1183-1190.

70 Prasad R, Garg R, Sanjay, et al. A study on prevalence of allergic bronchopulmonary aspergillosis in patients of bronchial asthma. Internet J Pulm Med 2008; 9: DOI: 10.5580/1418.

71 Sarkar A, Mukherjee A, Ghoshal AG, et al. Occurrence of allergic bronchopulmonary mycosis in patients with asthma: an Eastern India experience. Lung India 2010; 27: 212-216.

72 Ghosh T, Dey A, Biswas D, et al. Aspergillus hypersensitivity and allergic bronchopulmonary aspergillosis among asthma patients in eastern India. J Indian Med Assoc 2010; 108: 863-865.

73 Rosenberg M, Patterson R, Mintzer R, et al. Clinical and immunologic criteria for the diagnosis of allergic bronchopulmonary aspergillosis. Ann Intern Med 1977; 86: 405-414.

74 Wang JLF, Patterson R, Rosenberg M, et al. Serum IgE and IgG antibody activity against Aspergillus fumigatus as a diagnostic aid in allergic bronchopulmonary aspergillosis. Am Rev Respir Dis 1978; 117: 917-927.

75 Shah A. Allergic bronchopulmonary aspergillosis: an emerging disease in India. Indian J Chest Dis Allied Sci 1994; 36: $169-172$.

76 Scadding JG. The bronchi in allergic aspergillosis. Scand J Respir Dis 1967; 48: 372-377.

77 Patterson R, Greenberger PA, Halwig JM, et al. Allergic bronchopulmonary aspergillosis: natural history and classification of early disease by serologic and roentgenographic studies. Arch Intern Med 1986; 146: 916-918.

78 Glancy JJ, Elder JL, McAleer R. Allergic bronchopulmonary fungal disease without clinical asthma. Thorax 1981; 36: 345-349.

79 Berkin KE, Vernon DRH, Kerr JW. Lung collapse caused by allergic bronchopulmonary aspergillosis in nonasthmatic patients. Br Med J 1982; 285: 552-553.

80 Hoshino H, Tagaki S, Kon H, et al. Allergic bronchopulmonary aspergillosis due to Aspergillus niger without bronchial asthma. Respiration 1999; 66: 369-372.

81 Sanchez-Alarcos JMF, Martinez-Cruz R, Ortega L, et al. ABPA mimicking bronchogenic cancer. Allergy 2001; 56: 80-81.

82 Shah A, Maurya V, Panjabi C, et al. Allergic bronchopulmonary aspergillosis without clinical asthma caused by Aspergillus niger. Allergy 2004; 59: 236-237.

83 Koh WJ, Han J, Kim TS, et al. Allergic bronchopulmonary aspergillosis coupled with broncholithiasis in a nonasthmatic patient. J Korean Med Sci 2007; 22: 365-368.

84 Ricketti AJ, Greenberger PA, Patterson R. Immediate-type reactions in patients with allergic bronchopulmonary aspergillosis. J Allergy Clin Immunol 1983; 71: 541-545.

85 Shah A, Bhagat R, Panchal N. Allergic bronchopulmonary aspergillosis with clubbing and cavitation. Indian Pediatr 1993; 30: 248-251.

86 Shah A, Kala J, Sahay S. Allergic bronchopulmonary aspergillosis with hilar adenopathy in a 42-month-old boy. Pediatr Pulmonol 2007; 42: 747-748.

87 Imbeau SA, Cohen M, Reed CE. Allergic bronchopulmonary aspergillosis in infants. Am J Dis Child 1977; 131: $1127-1130$.

88 Shah A. Allergic bronchopulmonary aspergillosis: an Indian perspective. Curr Opin Pulm Med 2007; 13: 72-80.

89 McCarthy DS, Pepys J. Allergic bronchopulmonary aspergillosis. Clinical immunology: 1. Clinical features. Clin Allergy 1971; 1: 261-286.

90 Safirstein BH, D'Souza MF, Simon G, et al. Five year follow up of bronchopulmonary aspergillosis. Am Rev Respir Dis 1973; 108: 450-459.

91 Shah A, Panchal N, Panjabi C. Allergic bronchopulmonary aspergillosis: a review from India. Allergy Clin Immunol Int J World Allergy Org 2003: Suppl. 1, 104.

92 Shah A. Allergic bronchopulmonary aspergillosis. Allergy Clin Immunol Int J World Allergy Org 2005; 17: 172-180.

93 Panchal N, Bhagat R, Pant C, et al. Allergic bronchopulmonary aspergillosis: the spectrum of computed tomography appearances. Respir Med 1997; 91: 213-219.

94 Shah A, Panchal N, Agarwal AK. Allergic bronchopulmonary aspergillosis: the spectrum of roentgenologic appearances. Indian J Radiol Imag 1999; 9: 107-112.

95 McCarthy DS, Simon G, Hargeave FE. The radiological appearances in allergic bronchopulmonary aspergillosis. Clin Radiol 1970; 21: 366-375.

96 Mintzer RA, Roger LF, Kruglik GD. The spectrum of radiologic findings in allergic bronchopulmonary aspergillosis. Radiology 1978; 127: 301-307.

97 Phelan MS, Kerr IH. Allergic bronchopulmonary aspergillosis: the radiological appearances during long-term follow up. Clin Radiol 1984; 35: 385-392.

98 Shah A. Allergic bronchopulmonary and sinus aspergillosis: the roentgenologic spectrum. Front Biosci 2003; 8: e138-e146.

99 Hantsch CE, Tanus T. Allergic bronchopulmonary aspergillosis with adenopathy. Ann Intern Med 1991; 115: 546-547. 
100 Shah A, Aggarwal AK, Chugh IM. Hilar adenopathy in allergic bronchopulmonary aspergillosis. Ann Allergy Asthma Immunol 1999; 82: 504-506.

101 Shah A, Bhagat R, Panchal N, et al. Allergic bronchopulmonary aspergillosis with middle lobe syndrome and allergic Aspergillus sinusitis. Eur Respir J 1993; 6: 917-918.

102 Greenberger PA, Patterson R. Allergic bronchopulmonary aspergillosis. Model of bronchopulmonary disease with defined serologic, radiologic, pathologic and clinical findings from asthma to fatal destructive lung disease. Chest 1987; 91: Suppl. 6, 165S-171S.

103 Panchal N, Pant CS, Bhagat R, et al. Central bronchiectasis in allergic bronchopulmonary aspergillosis: comparative evaluation of computed tomography of the thorax with bronchography. Eur Respir J 1994; 7: 1290-1293.

104 Fisher MR, Mendelson EB, Mintzer RA, et al. Use of linear tomography to confirm the diagnosis of allergic bronchopulmonary aspergillosis. Chest 1985; 87: 499-502.

105 Shah A, Pant CS, Bhagat R, et al. Computed tomography in childhood allergic bronchopulomonary aspergillosis. Pediatr Radiol 1992; 22: 227-228.

106 Webb WR, Muller NL, Naidich DP, eds. High-resolution CT of the Lung. 2nd Edn. New York, Lippincott Williams and Wilkins, 1996; pp. 257-258.

107 Mitchell TAM, Hamilos DL, Lynch DA, et al. Distribution and severity of bronchiectasis in allergic bronchopulmonary aspergillosis (ABPA). J Asthma 2000; 37: 65-72.

108 Hansell DM, Strickland B. High-resolution computed tomography in pulmonary cystic fibrosis. Br J Radiol 1989; 62: 1-5.

109 Shah A, Khan ZU, Chaturvedi S, et al. Allergic bronchopulmonary aspergillosis with co-existent aspergilloma: a long term follow up. J Asthma 1989; 26: 109-115.

110 Agarwal AK, Bhagat R, Panchal N, et al. Allergic bronchopulmonary aspergillosis with aspergilloma mimicking fibrocavitory pulmonary tuberculosis. Asian Pac J Allergy Immunol 1996; 14: 5-8.

111 Goyal R, White CS, Templeton PA, et al. High attenuation mucous plugs in allergic bronchopulmonary aspergillosis: CT appearance. J Comput Assist Tomogr 1992; 16: 649-650.

112 Murphy D, Lane DJ. Pleural effusion in allergic bronchopulmonary aspergillosis: two case reports. Br J Dis Chest 1981; 75: 91-95.

113 Bhagat R, Shah A, Jaggi OP, et al. Concomitant allergic bronchopulmonary aspergillosis and allergic Aspergillus sinusitis with an operated aspergilloma. J Allergy Clin Immunol 1993; 91: 1094-1096.

114 O'Connor TM, O'Donnell A, Hurley M, et al. Allergic bronchopulmonary aspergillosis: a rare cause of pleural effusion. Respirology 2001; 6: 361-363.

115 Ricketti AJ, Greenberger PA, Glassroth J. Spontaneous pneumothorax in allergic bronchopulmonary aspergillosis. Arch Intern Med 1984; 144: 151-152.

116 Judson MA, Marshall C, Beale G, et al. Pneumothorax and bronchopleural fistula during treatment of allergic bronchopulmonary aspergillosis. South Med J 1993; 86: 1061-1063.

117 Lynch DA. Imaging of asthma and allergic bronchopulmonary mycosis. Radiol Clin North Am 1998; 36: 129-142.

118 Angus RM, Davies ML, Cowan MD, et al. Computed tomographic scanning of the lung in patients with allergic bronchopulmonary aspergillosis and in asthmatic patients with a positive skin test to Aspergillus fumigatus. Thorax 1994; 49: 586-589.

119 Knutsen AP, Bush RK, Demain JG, et al. Fungi and allergic lower respiratory tract diseases. J Allergy Clin Immunol 2012; 129: 280-291.

120 Agarwal R, Aggarwal AN, Gupta D, et al. Aspergillus hypersensitivity and allergic bronchopulmonary aspergillosis in patients with bronchial asthma: systematic review and meta-analysis. Int J Tuberc Lung Dis 2009; 13: 936-944.

121 Hutcheson PS, Knutsen AP, Regent AJ, et al. A twelve year longitudinal study of Aspergillus sensitivity in patients with cystic fibrosis. Chest 1996; 110: 363-366.

122 Nikolaizik WH, Crameri R, Blaser K, et al. Skin test reactivity to recombinant Aspergillus fumigatus allergen I/a in patients with cystic fibrosis. Int Arch Allergy Immunol 1996; 111: 403-408.

123 Nikolaizik WH, Weichel M, Blaser K, et al. Intracutaneous tests with recombinant allergens in cystic fibrosis patients with allergic bronchopulmonary aspergillosis and Aspergillus allergy. Am J Respir Crit Care Med 2002; 165: 916-921.

124 Patterson R, Roberts M. IgE and IgG antibodies against Aspergillus fumigatus in sera of patients with bronchopulmonary allergic aspergillosis. Int Arch Allergy 1974; 46: 150-160.

125 Brummund W, Resnick A, Fink JM, et al. Aspergillus fumigatus-specific antibodies in allergic bronchopulmonary aspergillosis and aspergilloma: evidence for a polyclonal antibody response. J Clin Microbiol 1987; 25: 5-9.

126 Crameri R, Hemmann S, Ismail C, et al. Disease-specific recombinant allergens for the diagnosis of allergic bronchopulmonary aspergillosis. Int Immunol 1998; 10: 1211-1216.

127 Kurup VP, Banerjee B, Hemmann S, et al. Selected recombinant Aspergillus fumigatus allergens bind specifically to IgE in ABPA. Clin Exp Allergy 2000; 30: 988-993.

128 Hemmann S, Nikolaizik WH, Schoni MH, et al. Differential IgE recognition of recombinant Aspergillus fumigatus allergens by cystic fibrosis patients with allergic bronchopulmonary aspergillosis or Aspergillus allergy. Eur J Biochem 1998; 28: 1155-1160.

129 Knutsen AP, Hutcheson PS, Slavin RG, et al. IgE antibody to Aspergillus fumigatus recombinant allergens in cystic fibrosis patients with allergic bronchopulmonary aspergillosis. Allergy 2004; 59: 198-203.

130 Greenberger PA, Miller TP, Roberts M, et al. Allergic bronchopulmonary aspergillosis in patients with and without evidence of bronchiectasis. Ann Allergy 1993; 70: 333-338.

131 Wark PA, Saltos N, Simpson J, et al. Induced sputum eosinophils and neutrophils and bronchiectasis severity in allergic bronchopulmonary aspergillosis. Eur Respir J 2000; 16: 1095-1101.

132 Ouchterlony Ö. Diffusion-in-gel methods for immunological analysis. Prog Allergy 1958; 5: 1-78.

133 Denning DW. Chronic forms of pulmonary aspergillosis. Clin Microbiol Infect 2001; 7: Suppl. 2, 25-31.

134 Denning DW, Riniotis K, Dobrashian R, et al. Chronic cavitary and fibrosing pulmonary and pleural aspergillosis: case series, proposed nomenclature change, and review. Clin Infect Dis 2003; 37: Suppl. 3, S265-S280.

135 Denning DW, Park S, Lass-Florl C, et al. High-frequency triazole resistance found in nonculturable Aspergillus fumigatus from lungs of patients with chronic fungal disease. Clin Infect Dis 2011; 52: 1123-1129.

136 Nichols D, Dopico GA, Braun S, et al. Acute and chronic pulmonary function changes in allergic bronchopulmonary aspergillosis. Am J Med 1979; 67: 631-637. 
137 Panjabi C, Shah A. Lung functions in allergic bronchopulmonary aspergillosis. Respirology 2006; 11: A38.

138 Patterson R, Greenberger PA, Radin RC, et al. Allergic bronchopulmonary aspergillosis: staging as an aid to management. Ann Intern Med 1982; 96: 286-291.

139 Greenberger PA, Patterson R. Diagnosis and management of allergic bronchopulmonary aspergillosis. Ann Allergy 1986; 56: 444-448.

140 Shah A, Bhagat R, Pant K, et al. Allergic bronchopulmonary aspergillosis with aspergilloma: exacerbation after prolonged remission. Indian J Tuberc 1993; 40: 39-41.

141 Ramachandran S, Shah A, Pant K, et al. Allergic bronchopulmonary aspergillosis and Candida albicans colonization of the respiratory tract in corticosteroid dependent asthma. Asian Pac J Allergy Immunol 1990; 8: 123-126.

142 Agarwal R, Khan A, Gupta D, et al. An alternate method of classifying allergic bronchopulmonary aspergillosis based on high-attenuation mucus. PLoS One 2010; 5: e15346.

143 Fink JN. Therapy of allergic bronchopulmonary aspergillosis. Indian J Chest Dis Allied Sci 2000; 42: 221-224.

144 Rosenberg M, Patterson R, Roberts M, et al. The assessment of immunologic and clinical changes occurring during corticosteroid therapy for allergic bronchopulmonary aspergillosis. Am J Med 1978; 64: 599-606.

145 Wang JLF, Patterson R, Roberts M, et al. The management of allergic bronchopulmonary aspergillosis. Am Rev Respir Dis 1979; 120: 87-92.

146 Vlahakis NE, Aksamit TR. Diagnosis and treatment of allergic bronchopulmonary aspergillosis. Mayo Clin Proc 2001; 76: 930-938.

147 Agarwal R, Gupta D, Aggarwal AN, et al. Allergic bronchopulmonary aspergillosis: lessons from 126 patients attending a chest clinic in north India. Chest 2006; 130: 442-448.

148 Patterson K, Strek ME. Allergic bronchopulmonary aspergillosis. Proc Am Thorac Soc 2010; 7: 237-244.

149 Shah A, Panjabi C. Biweekly therapy with prednisolone is effective in the management of allergic bronchopulmonary aspergillosis. Allergy Clin Immunol Int - J World Allergy Org, 2005: Suppl. 1, 113.

150 Skowronski E, Fitzgerald DA. Life-threatening allergic bronchopulmonary aspergillosis in a well child with cystic fibrosis. Med J Aust 2005; 182: 482-483.

151 Thomson JM, Wesley A, Byrnes CA, et al. Pulse intravenous methylprednisolone for resistant allergic bronchopulmonary aspergillosis in cystic fibrosis. Pediatr Pulmonol 2006; 41: 164-170.

152 Cohen-Cymberknoh M, Blau H, Shoseyov D, et al. Intravenous monthly pulse methylprednisolone treatment for ABPA in patients with cystic fibrosis. J Cyst Fibros 2009; 8: 253-257.

153 Malo JL. Antifungal therapy for allergic bronchopulmonary aspergillosis. J Allergy Clin Immunol 2003; 111: 934-935.

154 Leon EE, Craig TJ. Antifungals in the treatment of allergic bronchopulmonary aspergillosis. Ann Allergy Asthma Immunol 1999; 82: 511-517.

155 Stevens DA, Schwartz HJ, Lee JY, et al. A randomized trial of itraconazole in allergic bronchopulmonary aspergillosis. N Engl J Med 2000; 342: 756-762.

156 Wark PA, Hensley MJ, Saltos N, et al. Anti-inflammatory effect of itraconazole in stable allergic bronchopulmonary aspergillosis: a randomized controlled trial. J Allergy Clin Immunol 2003; 111: 952-957.

157 Pasqualotto AC, Denning DW. Generic substitution of itraconazole resulting in sub-therapeutic levels and resistance. Int J Antimicrob Agents 2007; 30: 93-94.

158 Howard SJ, Cerar D, Anderson MJ, et al. Frequency and evolution of azole resistance in Aspergillus fumigatus associated with treatment failure. Emerg Infect Dis 2009; 15: 1068-1076.

159 Howard SJ, Pasqualotto AC, Denning DW. Azole resistance in allergic bronchopulmonary aspergillosis and Aspergillus bronchitis. Clin Microbiol Infect 2010; 16: 683-688.

160 Hilliard T, Edwards S, Buchdahl R, et al. Voriconazole therapy in children with cystic fibrosis. J Cyst Fibros 2005; 4: 215-220.

161 Mulliez P, Croxo C, Roy-Saint Georges F, et al. Aspergillose broncho-pulmonaire allergique traitée par voriconazole [Allergic broncho-pulmonary aspergillosis treated with voriconazole]. Rev Mal Respir 2006; 23: 93-94.

162 Bandres Gimeno R, Munoz Martinez MJ. Respuesta terapéutica prolongada a voriconazol en un caso de broncoaspergilosis alérgica [Prolonged therapeutic response to voriconazole in a case of allergic bronchopulmonary aspergillosis]. Arch Bronconeumol 2007; 43: 49-51.

163 Erwin GE, Fitzgerald JE. Case report: allergic bronchopulmonary aspergillosis and allergic fungal sinusitis successfully treated with voriconazole. J Asthma 2007; 44: 891-895.

164 Chishimba L, Niven RM, Cooley J, et al. Voriconazole and posaconazole improve asthma severity in allergic bronchopulmonary aspergillosis and severe asthma with fungal sensitization. J Asthma 2012; 49: 423-433.

165 Clancy CJ, Nguyen MH. Long-term voriconazole and skin cancer: is there cause for concern? Curr Infect Dis Rep 2011; 13: 536-543.

166 van der Ent CK, Hoekstra H, Rijkers GT. Successful treatment of allergic bronchopulmonary aspergillosis with recombinant anti-IgE antibody. Thorax 2007; 62: 276-277.

167 Zirbes JM, Milla CE. Steroid-sparing effect of omalizumab for allergic bronchopulmonary aspergillosis and cystic fibrosis. Pediatr Pulmonol 2008; 43: 607-610.

168 Kanu A, Patel K. Treatment of allergic bronchopulmonary aspergillosis (ABPA) in CF with anti-IgE antibody (omalizumab). Pediatr Pulmonol 2008; 43: 1249-1251.

169 Perez-de-Llano LA, Vennera MC, Parra A, et al. Effects of omalizumab in Aspergillus-associated airway disease. Thorax 2011; 66: 539-540.

170 Tillie-Leblond I, Germaud P, Leroyer C, et al. Allergic bronchopulmonary aspergillosis and omalizumab. Allergy 2011; 66: 1254-1256.

171 Collins J, Devos G, Hudes G, et al. Allergic bronchopulmonary aspergillosis treated successfully for one year with omalizumab. J Asthma Allergy 2012; 5: 65-70.

172 Nepomuceno IB, Esrig S, Moss RB. Allergic bronchopulmonary aspergillosis in cystic fibrosis: role of atopy and response to itraconazole. Chest 1999; 115: 364-370.

173 Mastella G, Rainisio M, Harms HK, et al. Allergic bronchopulmonary aspergillosis in cystic fibrosis. A European epidemiological study. Eur Respir J 2000; 16: 464-471.

174 Geller DE, Kaplowitz H, Light MJ, et al. Allergic bronchopulmonary aspergillosis in cystic fibrosis. Reported prevalence, regional distribution, and patient characteristics. Chest 1999; 116: 639-646. 

disease: COPD as a risk factor for ABPA? Med Mycol 2010; 48: 988-994.

176 Mir E, Shah A. Allergic bronchopulmonary aspergillosis in a patient with chronic obstructive pulmonary disease. Prim Care Respir J 2012; 21: 111-114.

177 Eppinger TM, Greenberger PA, White DA, et al. Sensitization to Aspergillus species in the congenital neutrophil disorders chronic granulomatous disease and hyper-IgE syndrome. J Allergy Clin Immunol 1999; 104: $1265-1272$.

178 Sharma B, Sharma M, Bondi E, et al. Kartagener's syndrome associated with allergic bronchopulmonary aspergillosis. Med Gen Med 2005; 7: 25.

179 Taylor RG, Joyce H, Gross E, et al. Bronchial reactivity to inhaled histamine and annual rate of decline in FEV1 in male smokers and ex-smokers. Thorax 1985; 40: 9-16.

180 Burrows B, Halonen M, Barbee RA, et al. The relationship of serum immunoglobulin E to cigarette smoking. Am Rev Respir Dis 1981; 124: 523-525.

181 Taylor RG, Gross E, Joyce H, et al. Smoking, allergy and the differential white blood cell count. Thorax 1985; 40: 17-22.

182 Brightling CE, Monteiro W, Ward R, et al. Sputum eosinophilia and short-term response to prednisolone in chronic obstructive pulmonary disease: a randomized controlled trial. Lancet 2000; 356: 1480-1485.

183 Dye JA, Adler KB. Effects of cigarette smoke on epithelial cells of the respiratory tract. Thorax 1994; 49: 825-834.

184 Patterson R. Allergic bronchopulmonary aspergillosis: a historical perspective. Immunol Allergy Clin North Am 1998; 18: 471-478.

185 Chowdhary A, Agarwal K, Kathuria S, et al. Allergic bronchopulmonary mycosis due to fungi other than Aspergillus: a global overview. Crit Rev Microbiol 2013 [In press DOI: 10.3109/1040841X.2012.754401].

186 Shah A, Panchal N, Agarwal AK. Concomitant allergic bronchopulmonary aspergillosis and allergic Aspergillus sinusitis: a review of an uncommon association. Clin Exp Allergy 2001; 31: 1896-1905.

187 Sharma P, Agarwal AK, Shah A. Formation of an aspergilloma in a patient with allergic bronchopulmonary aspergillosis on corticosteroid therapy. Indian J Chest Dis Allied Sci 1998; 40: 269-273.

188 Shah A, Panjabi C. Contemporaneous occurrence of allergic bronchopulmonary aspergillosis, allergic Aspergillus sinusitis, and aspergilloma. Ann Allergy Asthma Immunol 2006; 96: 874-878.

189 Katzenstein AL, Sale SR, Greenberger PA. Allergic Aspergillus sinusitis: a newly recognised form of sinusitis. J Allergy Clin Immunol 1983; 72: 89-93.

190 Shah A, Khan ZU, Sircar M, et al. Allergic Aspergillus sinusitis: an Indian report. Respir Med 1990; 84: $249-251$.

191 Millar JW, Johnston A, Lamb D. Allergic aspergillosis of the maxillary sinuses. Thorax 1981; $36: 710$.

192 Shah A, Sircar M. Sensitization to Aspergillus antigens in perennial rhinitis. Asian Pac J Allergy Immunol 1991; 9: 137-139.

193 Sahay S, Shah A. Allergic rhinitis: Aspergillus sensitisation increases the severity of sinusitis in "blockers" as compared to "sneezers and runners". Allergy 2008; 63: 73.

194 Bartynski JM, McCaffrey TV, Frigas E. Allergic fungal sinusitis secondary to dematiaceous fungi: Curvularia lunata and Alternaria. Otolaryngol Head Neck Surg 1990; 103: 32-39.

195 Manning SC, Schaefer SD, Close LG, et al. Culture-positive allergic fungal sinusitis. Arch Otolaryngol Head Neck Surg 1991; 117: 174-178.

196 Corey JP, Delsupehe KG, Ferguson BJ. Allergic fungal sinusitis: allergic, infectious, or both? Otolaryngol Head Neck Surg 1995; 113: 110-119.

197 Schubert MS, Goetz DW. Evaluation and treatment of allergic fungal sinusitis. I. Demographics and diagnosis J Allergy Clin Immunol 1998; 102: 387-394.

198 Mukherji SK, Figueroa RE, Ginsberg LE, et al. Allergic fungal sinusitis: CT findings. Radiology 1998; 207: 417-422

199 Schubert MS. Allergic fungal sinusitis: pathogenesis and management strategies. Drugs 2004; 64: 363-374.

200 Sher TH, Schwartz HJ. Allergic Aspergillus sinusitis with concurrent allergic bronchopulmonary Aspergillus: report of a case. J Allergy Clin Immunol 1988; 81: 844-846.

201 Schwartz HJ, Witt WJ, Sher TH. Allergic bronchopulmonary aspergillosis and allergic aspergillus sinusitis: case report. Ann Allergy 1992; 69: 447-448.

202 Venarske DL, deShazo RD. Sinobronchial allergic mycosis: the SAM syndrome. Chest 2002; 121: 1670-1676.

203 Braun JJ, Pauli G, Schultz P, et al. Allergic fungal sinusitis associated with allergic bronchopulmonary aspergillosis: an uncommon sinobronchial allergic mycosis. Am J Rhinol 2007; 21: 412-416.

204 Prasad R, Garg R, Sanjay. Concomitant allergic bronchopulmonary aspergillosis and allergic fungal sinusitis. Indian J Med Sci 2007; 61: 532-534.

205 Diwakar A, Panjabi C, Shah A. Allergic bronchopulmonary aspergillosis, allergic Aspergillus sinusitis and their cooccurrence. Open Allergy J 2008; 1: 52-61.

206 Cody DT 2nd, Neel HB 3rd, Ferreiro JA, et al. Allergic fungal sinusitis: the Mayo clinic experience. Laryngoscope 1994; 104: 1074-1079.

207 Campbell JM, Graham M, Gray HC, et al. Allergic fungal sinusitis in children. Ann Allergy Asthma Immunol 2006; 96: 286-290

208 Kurashima A. Analysis of the course of non-invasive pulmonary aspergillosis. Jpn J Med Mycol 1997; 38: 167-174

209 McCarthy DS, Pepys J. Pulmonary aspergilloma: clinical immunology. Clin Allergy 1973; 3: 57-70.

210 Ein ME, Wallace RJ Jr, Williams TW. Allergic bronchopulmonary aspergillosis-like syndrome consequent to aspergilloma. Am Rev Respir Dis 1979; 119: 811-820.

211 Pendleton M, Denning DW. Multifocal pulmonary aspergillomas: case series and review. Ann NY Acad Sci 2012; 1272: $58-67$.

212 Shah A. Concurrent allergic bronchopulmonary aspergillosis and aspergilloma: is it a more severe form of the disease? Eur Respir Rev 2010; 19: 261-263.

213 Agarwal R, Aggarwal AN, Garg M, et al. Allergic bronchopulmonary aspergillosis with aspergilloma: an immunologically severe disease with poor outcome. Mycopathologia 2012; 174: 193-201.

214 Shah A. Asthma and Aspergillus. Indian J Chest Dis Allied Sci 2004; 46: 167-170.

215 Panjabi C, Shah A. Allergic Aspergillus sinusitis and its association with allergic bronchopulmonary aspergillosis. Asia Pac Allergy 2011; 1: 130-137. 